\title{
Molecular Engineering of Intensely Near-Infrared Absorbing Excited-States in Highly Conjugated Oligo(Porphinato)Zinc-(Polypyridyl)Metal(II) Supermolecules
}

Timothy V. Duncan, Tomoya Ishizuka, and Michael J. Therien

Department of Chemistry, University of Pennsylvania, Philadelphia, PA 19104

\section{Supporting Information Section}

\section{Synthesis and Characterization of New Compounds.}

Materials. All manipulations were carried out under nitrogen or argon previously passed through an $\mathrm{O}_{2}$ scrubbing tower (Schweitzerhall R3-11 catalyst) and a drying tower (Linde 3-Å molecular sieves) unless otherwise stated. Air sensitive solids were handled in a Braun 150-M glove box. Standard Schlenk techniques were employed to manipulate air-sensitive solutions. All solvents utilized in this work were obtained from Fisher Scientific (HPLC Grade). $\mathrm{CH}_{2} \mathrm{Cl}_{2}$ and tetrahydrofuran (THF) were distilled from $\mathrm{CaH}_{2}$ and $\mathrm{K} / 4$-benzoylbiphenyl, respectively, under $\mathrm{N}_{2}$. Triethyleamine (TEA) was dried over $\mathrm{KOH}$ pellets and distilled under vacuum. All NMR solvents were used as received. The catalysts $\mathrm{Pd}\left(\mathrm{PPh}_{3}\right)_{4}$ and tris(dibenzylideneacetone)-dipalladium(0) $\left(\mathrm{Pd}_{2} \mathrm{dba} 3\right)$, as well as triphenylarsine $\left(\mathrm{AsPh}_{3}\right)$, were purchased from Strem Chemicals. Flash and size exclusion column chromatography were performed on the bench top, using respectively silica gel (EM Science, 230-400 mesh) and Bio-Rad Bio-Beads SX-1 as media.

Characterization Instrumentation. NMR spectra were recorded on $250 \mathrm{MHz}$ AMX-250 or 500 MHz AMX-500 Brüker spectrometers. Chemical shifts for ${ }^{1} \mathrm{H}$ NMR 
spectra are reported relative to tetramethylsilane (TMS) in deuterated solvent (TMS, $\delta=$ $0.00 \mathrm{ppm})$. All $J$ values are reported in Hertz.

Mass spectra were acquired at the Mass Spectrometry Center at the University of Pennsylvania. MALDI-TOF mass spectroscopic data were obtained with a Perspective Voyager DE instrument in the Laboratory of Professor William DeGrado (Department of Biophysics, University of Pennsylvania). Samples were prepared as micromolar solutions in THF, and dithranol (Aldrich) was utilized as the matrix.

A. Terpyridine Ligands. The ligand 4'-bromo-2,2';6',2"'-terpyridine (brtpy) was synthesized from the starting material 2,6-bis(2-pyridyl)-4(1H)-pyridone (1), ${ }^{1,2}$ phosphorous pentabromide $\left(\mathrm{PBr}_{5}\right)$ and phosphorous oxybromide $\left(\mathrm{POBr}_{3}\right)$ using a previously reported method that is depicted in Scheme $\mathrm{S} 1 .^{3}$

Two general strategies have been reported in the literature for the preparation of pyrrolidine-functionalized terpyridines. In the first, ${ }^{4,5}$ commercially available 4pyrrolidin-1-yl-pyridine is chlorinated or organostannylated in the 2- and/or 6-positions via the use of the superbasic BuLi-LiDMAE ${ }^{6}$ lithium regent; these intermediates can then in principle be combined with each other or with commercially available 2chloropyridine via Stille-type palladium-mediated cross coupling reactions ${ }^{7}$ to form the desired 4'-pyrrolidin-1-yl-2,2';6',2”-terpyridine (Pyr $\mathbf{1}_{1}$-tpy) and 4,4',4'”-tripyrrolidin-1-yl2,2';6',2'-terpyridine ( $\mathbf{P y r}_{\mathbf{3}}$-tpy) products, respectively. While Ishii and coworkers ${ }^{5}$ report the successful isolation of both $\mathbf{P y r}_{1}$-tpy and $\mathbf{P y r}_{3}$-tpy via the use of this synthetic strategy, Martineau and coworkers ${ }^{4}$, though successfully isolating the ligand $\mathbf{P y r}_{\mathbf{1}}$-tpy, experienced extreme difficulty in isolating $\mathbf{P y r}_{\mathbf{3}}$-tpy via the reaction of 2-tributylstannyl4-pyrrolidin-1-yl-pyridine with 2,6-dichloro-4-pyrrolidin-1-yl-pyridine, even after the 
addition of a large molar excess of the organostannyl pyridine reagent, obtaining the desired product in only a trace amount. Our own efforts to use this procedure for the synthesis of $\mathbf{P y r}_{\mathbf{3}}$-tpy, which were performed prior to the publication of Martineau's work, were similarly fruitless, as we isolated primarily the 4,4'-pyrrolin-1-yl-6'-chloro2,2'-bipyridine monofunctionalized intermediate. The use of brominated starting materials did not improve the reaction yield. Presumably, the first functionalization of 2,6-halo-4-pyrrolin-1-yl with pyrrolin-1-yl-pyridine deactivates the second halogen due to the strong electron-donating influence of the pyrrolinyl substituent.

In any case, due to the difficulty of preparing $\mathbf{P y r}_{\mathbf{3}}$-tpy and the low yields of isolated Pyr $\mathbf{P}_{1}$-tpy that we experienced using the Martineau/Ishii method, we turned to a patent published by Wieprecht, et al., ${ }^{8}$ which reported the successful synthesis of $\mathbf{P y r}_{\mathbf{1}^{-}}$ tpy and $\mathbf{P y r}_{3}$-tpy via multistep ring-construction, chlorination, and then amination, although we bypassed the ring-construction steps via an alternate synthetic strategy. In the case of $\mathbf{P y r}_{\mathbf{1}}$-tpy, the 4'-chloro-2,2';6'2'-terpyridine (2) intermediate could be easily synthesized from the aforementioned 2,6-bis(2-pyridyl)-4(1H)-pyridone (1), which is commercially available, phosphorous pentachloride $\left(\mathrm{PCl}_{5}\right)$ and phosphorous oxychloride $\left(\mathrm{POCl}_{3}\right)$ in high $(>90 \%)$ yield via literature procedure (Scheme S1). ${ }^{9}$ For $\mathbf{P y r}_{3}$-tpy, the 4,4',4"'-trichloro-2,2';6',2'"-terpyridine (7) intermediate was prepared from 2,2':6',2"'terpyridine $(\mathbf{3})^{10}$ (also commercially available) by an optimized four-step procedure originally developed by Case (Scheme S2). ${ }^{11}$ Finally, $\mathbf{P y r}_{1}$-tpy and $\mathbf{P y r}_{\mathbf{3}}$-tpy were prepared in high yield from the appropriately chlorinated terpyridines ( 2 and $\mathbf{7 ,}$ respectively) by following a modified procedure for the alkyl-amination of chloro- 
substituted terpyridines originally reported by Constable (Schemes S1 and S2, respectively). $^{12}$

4'-pyrrolidin-1-yl-2,2';6',2'-terpyridine (Pyr ${ }_{1}$-tpy). 4'-chloro-2,2';6',2"'terpyridine (2) (400 mg, $3.21 \mathrm{mmol}$ ) and ferrous chloride tetrahydrate (639 mg, 1.49 mmol) were dissolved in 2-propanol $(50 \mathrm{~mL})$, yielding a brilliant purple solution. This solution was refluxed for twenty minutes, following which neat pyrrolidine $(\sim 2.2 \mathrm{~g}, 30$ mmol, $2.6 \mathrm{~mL}$ ) was added. The reaction mixture, which gradually turns brown-purple, was refluxed an additional 16 hours, after which it was cooled to room temperature and filtered to remove precipitated iron oxide. The filtrate was treated with excess $(\sim 200$ eqv.) ammonium hexafluorophosphate and diluted with water until a purple precipitate formed. This solid was collected by filtration, washed with water and ether, taken up in acetonitrile and then concentrated to a volume of approximately $5 \mathrm{~mL}$. The concentrated solution was made basic with $1 \mathrm{~N}$ aqueous $\mathrm{NaOH}$ solution $(2-3 \mathrm{~mL})$, and drops of $30 \%$ hydrogen peroxide solution were added while stirring until the purple color disappeared, leaving a brownish solution with copious off-white precipitate. The suspension was filtered and washed with water. The crude solid was then washed thoroughly with chloroform, and the filtrate was collected and evacuated to dryness, yielding the desired product as a tannish-white solid (288 mg, 64\%). ${ }^{1} \mathrm{H}$ NMR (500 MHz, $\left.\mathrm{CDCl}_{3}\right): \delta 8.66(\mathrm{~d}$, $2 \mathrm{H}, J=5.2 \mathrm{~Hz}), 8.60(\mathrm{~d}, 2 \mathrm{H}, J=8 \mathrm{~Hz}), 7.81(\mathrm{td}, 2 \mathrm{H}, J=7.5 \mathrm{~Hz}, J=1.9 \mathrm{~Hz}), 7.60(\mathrm{~s}$, 2H), $7.27(\mathrm{ddd}, 2 \mathrm{H}, J=7.5 \mathrm{~Hz}, J=5 \mathrm{~Hz}, J=1 \mathrm{~Hz}), 3.54(\mathrm{~m}, 4 \mathrm{H}), 2.05(\mathrm{~m}, 4 \mathrm{H})$. HRMS: $m / z=302.1521\left(\mathrm{M}^{+}\right.$Calculated $\left.\mathrm{C}_{19} \mathrm{H}_{18} \mathrm{~N}_{4}=302.1532\right)$.

2,2';6',2"-terpyridine-1,1',1"'-trioxide (4). 2,2';6',2"'-terpyridine (3) (10.0 g, $43.0 \mathrm{mmol}$ ) was added to a $250 \mathrm{~mL}$ round bottom flask equipped with stirbar and 
condenser. Glacial acetic acid $(50 \mathrm{~mL})$ was added along with $35 \mathrm{~mL} \mathrm{30 \%} \mathrm{hydrogen}$ peroxide solution. This mixture was heated to $90{ }^{\circ} \mathrm{C}$ for two hours, following which an additional $35 \mathrm{~mL} \mathrm{30 \%} \mathrm{hydrogen} \mathrm{peroxide} \mathrm{solution} \mathrm{was} \mathrm{added.} \mathrm{The} \mathrm{reaction} \mathrm{mixture} \mathrm{was}$ stirred at $90{ }^{\circ} \mathrm{C}$ for 18 hours. The mixture was then cooled to room temperature and poured onto $500 \mathrm{~mL}$ acetone; this mixture was allowed to sit at room temperature for approximately 2 hours, during which copious white crystals precipitated from solution. These were collected by filtration and washed with cold acetone to yield pure product (11.7 g, 95\%). ${ }^{1} \mathrm{H}$ NMR (500 MHz, $\left.\mathrm{D}_{2} \mathrm{O}\right): \delta 8.45(\mathrm{~d}, 2 \mathrm{H}, J=6.5 \mathrm{~Hz}), 7.88(\mathrm{~m}, 3 \mathrm{H}), 7.81$ (m $4 \mathrm{H}), 7.73(\mathrm{td}, 2 \mathrm{H}, J=6 \mathrm{~Hz}, J=2.4 \mathrm{~Hz})$.

4,4',4'-trinitro-2,2';6',2"-terpyridine-1,1',1'"-trioxide (5). 2,2';6',2"terpyridine-1,1',1"'-trioxide (4) $(2.154 \mathrm{~g}, 7.66 \mathrm{mmol})$ was added to a $250 \mathrm{~mL}$ round bottom flask equipped with stirbar. Concentrated H2SO4 $(7.5 \mathrm{~mL})$ was added and the mixture cooled $0{ }^{\circ} \mathrm{C}$ white purging with argon. $20 \%$ fuming $\mathrm{H}_{2} \mathrm{O}_{4}(1.8 \mathrm{~mL})$ was added, followed by fuming $\mathrm{HNO}_{3}(3.6 \mathrm{~mL})$. The reaction flask was then equipped with a condenser and heated to $100{ }^{\circ} \mathrm{C}$ for 1 hour under argon, followed by a 4 hour heating period at $120{ }^{\circ} \mathrm{C}$. After this time, the reaction mixture was cooled slightly and then poured onto ice. The resulting yellowish precipitate was filtered and washed with aqueous bicarbonate solution. The yellow solid was dissolved in a small quantity of pyridine and water was added until yellow crystals precipitated, which were collected by filtration to yield the desired product, which was used without further purification (1.02 g, 32\%). ${ }^{1} \mathrm{H}$ NMR $\left(500 \mathrm{MHz}, \mathrm{CHCl}_{3}\right): \delta 8.68(\mathrm{~s}, 2 \mathrm{H}), 8.57(\mathrm{~d}, 2 \mathrm{H}, J=5.3 \mathrm{~Hz}), 8.40(\mathrm{~d}$, $2 \mathrm{H}, J=12 \mathrm{~Hz}), 8.26(\mathrm{dd}, 2 \mathrm{H}, J=12 \mathrm{~Hz}, J=5.3 \mathrm{~Hz})$. 
4,4',4"-chloro-2,2';6',2"'-terpyridine (7). 4,4',4"-trinitro-2,2';6',2"'-terpyridine1,1',1'-trioxide (5) (570 mg, $1.37 \mathrm{mmol})$, dried under vacuum for 30 minutes, was added under argon to glacial acetic acid $(7 \mathrm{~mL})$ in a sealed $25 \mathrm{~mL}$ round bottom flask and the resulting suspension was brought to $60^{\circ} \mathrm{C}$. Acetyl chloride $(1 \mathrm{~mL})$ was added and the mixture was stirred at $70{ }^{\circ} \mathrm{C}$ for 2 hours. The mixture was then cooled slightly and poured onto ice and neutralized with aqueous $\mathrm{NaHCO}_{3}$. The resulting precipitate was collected by filtration, yielding the intermediate 4,4',4"'-trichloro -2,2';6',2"'-terpyridine1,1',1'-trioxide (6) as a yellow solid (706.9 mg). This was immediately added to $25 \mathrm{~mL}$ chloroform (suspension) and stirred at $0{ }^{\circ} \mathrm{C}$ under argon. $\mathrm{PCl}_{3}(2 \mathrm{~mL})$ was added and the resulting mixture was stirred at $0{ }^{\circ} \mathrm{C}$ for 1 hour, after which it was refluxed for 2 hours. The reaction mixture was poured onto ice and neutralized with aqueous bicarbonate solution, yielding a tan precipitate. It was determined by NMR that this material still contained a significant portion of 4,4',4"'-trichloro -2,2';6',2"'-terpyridine-1,1',1"'trioxide, so after drying the solid thoroughly under vacuum, it was resuspended in chloroform and the reaction with $\mathrm{PCl}_{3}$ was repeated in identical fashion. After neutralizing the final reaction mixture, the final product was isolated by filtration and identified as product (245.5 mg, 53\%). $\left.{ }^{1} \mathrm{H} \mathrm{NMR} \mathrm{(500} \mathrm{MHz,} \mathrm{CHCl}_{3}\right): \delta 9.18(\mathrm{~s}, 2 \mathrm{H}), 8.66$ $(\mathrm{d}, 2 \mathrm{H}, J=5.2 \mathrm{~Hz}), 8.58(\mathrm{dd}, 2 \mathrm{H}, J=17 \mathrm{~Hz}, J=2.5 \mathrm{~Hz}), 7.45(\mathrm{dd}, 2 \mathrm{H}, J=5.0 \mathrm{~Hz}, J=$ $1.8 \mathrm{~Hz})$.

4,4',4"-tripyrrolidin-1-yl-2,2';6',2"'-terpyridine (Pyr ${ }_{3}$-tpy). 4,4',4"'-chloro2,2';6',2"'-terpyridine (7) (22.6 mg, $0.067 \mathrm{mmol})$ and ferrous chloride tetrahydrate $(61.5$ $\mathrm{mg}$ ) were dissolved in 2-propanol $(50 \mathrm{~mL})$, yielding a brilliant purple solution. This solution was refluxed for twenty minutes, following which neat pyrrolidine $(\sim 2.2 \mathrm{~g}, 30$ 
mmol, $2.6 \mathrm{~mL}$ ) was added. The reaction mixture, which gradually turns brown-purple, was refluxed an additional 16 hours, after which it was cooled to room temperature and filtered to remove precipitated iron oxide. The filtrate was treated with excess $(\sim 200$ eqv.) ammonium hexafluorophosphate and diluted with water until a purple precipitate formed. This solid was collected by filtration, washed with water and ether, taken up in acetonitrile and then concentrated to a volume of approximately $5 \mathrm{~mL}$. The concentrated solution was made basic with $1 \mathrm{~N}$ aqueous $\mathrm{NaOH}$ solution $(2-3 \mathrm{~mL})$, and drops of $30 \%$ hydrogen peroxide solution were added while stirring until the purple color disappeared, leaving a brownish solution with copious off-white precipitate. The suspension was filtered and washed with water. The crude solid was then washed thoroughly with chloroform, and the filtrate was collected and evacuated to dryness, yielding the desired product as a tannish-white solid $(25.5 \mathrm{mg}, 86 \%) .{ }^{1} \mathrm{H}$ NMR $\left(500 \mathrm{MHz}, \mathrm{CDCl}_{3}\right): \delta 8.30(\mathrm{~d}$, $2 \mathrm{H}, J=9.6 \mathrm{~Hz}), 7.84(\mathrm{~d}, 2 \mathrm{H}, J=4.2 \mathrm{~Hz}), 7.54(\mathrm{~s}, 2 \mathrm{H}), 6.41(\mathrm{dd}, 2 \mathrm{H}, J=9.7 \mathrm{~Hz}, J=4.1$ $\mathrm{Hz}), 3.54(\mathrm{~m}, 4 \mathrm{H}), 3.45(\mathrm{~m}, 4 \mathrm{H}), 2.05(\mathrm{~m}, 8 \mathrm{H})$. HRMS: $m / z=441.2583\left((\mathrm{M}+\mathrm{H})^{+}\right.$ Calculated $\left.\mathrm{C}_{27} \mathrm{H}_{33} \mathrm{~N}_{4}=441.2768\right)$.

\section{B. Ruthenium and Osmium bis(terpyridine) Complexes. The complete} syntheses and characterizations of ruthenium(II) (4'-bromo-2,2';6',2'terpyridine)(2,2';6',2”-terpyridine) bis(hexafluorophosphate) (RuBr) and osmium(II) (4'-bromo-2,2';6',2'-terpyridine)(2,2';6',2'-terpyridine) bis(hexafluorophosphate) (OsBr) have been reported in an earlier work. ${ }^{3}$ However, as illustrated in Scheme S3, due to the present set of synthetic targets, which all contain the 4'-bromo-2,2';6',2'terpyridine ligand (brtpy) a slightly different approach was taken in this work whereby the brtpy ligand was added to the commercially available ruthenium $\left(\mathrm{RuCl}_{3}\right)$ and 
osmium $\left(\mathrm{NH}_{4} \mathrm{OsBr}_{6}\right)$ starting materials first, followed by addition of the unsubstituted 2,2';6',2"-terpyridine ligand (3) second (as opposed to adding them in the opposite order as in the previous work ${ }^{3}$.) Note that in the present work we have used $\mathrm{NH}_{4} \mathrm{OsBr}_{6}$ as the osmium source in place of the previously used $\mathrm{NH}_{4} \mathrm{OsCl}_{6}$, as the latter starting material was found to introduce unwanted chlorinated side products into the brominated osmium bis(terpyridine) product complexes.

Ruthenium(III) (4'-bromo-2,2';6',2'-terpyridine) trichloride (8). Ruthenium trichloride hydrate (950 mg, $4.2 \mathrm{mmol}$ ) and 4-bromo-2,2';6',2”-terpyridine (brtpy) (1.38 g, $4.42 \mathrm{mmol}$ ) were brought together in a $1 \mathrm{~L}$ round bottom flask with condenser and stirbar and refluxed in ethanol $(250 \mathrm{~mL})$ under air for 3 hours. The mixture was cooled in an ice bath and filtered. The brown solid was washed with ethanol and ether, leaving a brown powder that was used without further purification (1.6 g, 73\%). Due to the paramagnetic nature of this product and its poor solubility in most common organic solvents, this compound was not further characterized.

Osmium(III) (4'-bromo-2,2';6',2”-terpyridine) tribromide (9). Ammonium hexabromoosmate(IV) (400 mg, $0.567 \mathrm{mmol}$ ) and 4-bromo-2,2';6',2”-terpyridine (brtpy) (186 mg, $0.595 \mathrm{mmol}$ ) were brought together in a $500 \mathrm{~mL}$ round bottom flask with condenser and stirbar and refluxed in methanol $(200 \mathrm{~mL})$ under nitrogen atmosphere for 20 hours. The reaction mixture was cooled in an ice bath and filtered through a fritted funnel. The brown solid was washed with cold ethanol and then ether and was used without further purification $(306 \mathrm{mg}, 73 \%$ ). Due to the paramagnetic nature of this product and its poor solubility in most common organic solvents, this compound was not further characterized. 


\section{Ruthenium(II) (4'-bromo-2,2';6',2'-terpyridine)(2,2';6',2'-terpyridine)}

bis(hexafluorophosphate) (RuBr). 2,2';6',2"'-terpyridine (3) (350 mg, $1.5 \mathrm{mmol})$ and ruthenium(III) (4'-bromo-2,2';6',2”-terpyridyl) trichloride (8) (780 mg, 1.5 mmol) were combined in a $500 \mathrm{~mL}$ round bottom flask equipped with stirbar and condenser. Methanol (150 mL) was added and the flask was purged with nitrogen gas for 20 minutes. N-ethyl morpholine $(0.07 \mathrm{~mL}, 0.532 \mathrm{mmol})$ was added and the mixture was refluxed under nitrogen for 2 hours, during which time the reaction mixture turned dark red in color. After this duration, the reaction mixture was cooled and the solvent was removed, leaving a brownish-red solid. This crude material was purified by chromatography on silica using 90:9:1 acetonitrile: water: saturated aqueous $\mathrm{KNO}_{3}$ solution as eluent. The first and third orange bands were identified as [ruthenium(II) bis(4'-bromo-2,2';6',2'-terpyridine) $]^{2+}$ and [ruthenium(II) bis(2,2';6',2'-terpyridine) $]^{2+}$, respectively, while the middle band was identified as the desired product. This band was collected and concentrated on a rotary evaporator, and to this was added excess ammonium hexafluorophosphate. Water was added until a brownish-red precipitate formed, which was collected by filtration through a fritted funnel, then washed with water and ether to yield pure product (700 mg, 49\%). The side products were collected and worked up in similar fashion, for later use. ${ }^{1} \mathrm{H}$ NMR $\left(500 \mathrm{MHz}, \mathrm{CD}_{3} \mathrm{CN}\right): \delta 8.98$ (s, 2H), $8.74(\mathrm{~d}, 2 \mathrm{H}, J=8.2 \mathrm{~Hz}), 8.48(\mathrm{~d}, 2 \mathrm{H}, J=8.1 \mathrm{~Hz}), 8.42(\mathrm{t}, 2 \mathrm{H}, J=8.1 \mathrm{~Hz}), 7.92(\mathrm{~m}$, 4H), $7.35(\mathrm{~m}, 4 \mathrm{H}), 7.17(\mathrm{~m}, 4 \mathrm{H})$. HRMS $\left(\mathrm{ESI}^{+}\right) \mathrm{m} / \mathrm{z}=790.9730$ (calcd for $\left.\mathrm{C}_{30} \mathrm{H}_{21} \mathrm{~F}_{6} \mathrm{~N}_{6} \mathrm{BrPRu}\left(\mathrm{M}-\mathrm{PF}_{6}\right)^{+}=790.9696\right)$

Ruthenium(II) (4'-bromo-2,2';6',2'-terpyridine)(4'-pyrrolidin-1-yl2,2';6',2"-terpyridine) bis(hexafluorophosphate) (Pyr 1 RuBr). 4'-pyrrolidin-1-yl- 
2,2'; ' ',2'-terpyridine $\mathbf{P y r}_{1}$-tpy) (169 mg, $0.558 \mathrm{mmol}$ ) and ruthenium(III) (4'-bromo$2,2^{\prime} ; 6^{\prime}, 2^{\prime \prime}$-terpyridyl) trichloride (8) $(276 \mathrm{mg}, 0.531 \mathrm{mmol})$ were combined in a $250 \mathrm{~mL}$ round bottom flask equipped with stirbar and condenser. Methanol $(50 \mathrm{~mL})$ was added and the flask was purged with nitrogen gas for 20 minutes. N-ethyl morpholine (0.07 $\mathrm{mL}, 0.532 \mathrm{mmol}$ ) was added and the mixture was refluxed under nitrogen for 2 hours, during which time the reaction mixture turned dark red in color. After this duration, the reaction mixture was cooled and the solvent was removed, leaving a brownish-red solid. This crude material was purified by chromatography on silica using 90:9:1 acetonitrile: water: saturated aqueous $\mathrm{KNO}_{3}$ solution as eluent. The first and third orange bands were identified as [ruthenium(II) bis(4'-pyrrolidin-1-yl-2,2';6',2'-terpyridine) $]^{2+}$ and [ruthenium(II) bis(4'-bromo-2,2';6',2"'-terpyridine) $]^{2+}$, respectively, while the middle band was identified as the desired product. This band was collected and concentrated on a rotary evaporator, and to this was added excess ammonium hexafluorophosphate. Water was added until a brownish-red precipitate formed, which was collected by filtration through a fritted funnel, then washed with water and ether to yield pure product (165 mg, 30.9\%). The side products were collected and worked up in similar fashion, for later use. ${ }^{1} \mathrm{H}$ NMR $\left(500 \mathrm{MHz}, \mathrm{CD}_{3} \mathrm{CN}\right): \delta 8.94(\mathrm{~s}, 2 \mathrm{H}), 8.48(\mathrm{dd}, 2 \mathrm{H}, J=7.0 \mathrm{~Hz}, J=1.0$ $\mathrm{Hz}), 8.45(\mathrm{dd}, 2 \mathrm{H}, J=7.0 \mathrm{~Hz}, J=1.0 \mathrm{~Hz}), 7.93(\mathrm{td}, 2 \mathrm{H}, J=7.8 \mathrm{~Hz}, J=1.5 \mathrm{~Hz}), 7.85$ $(\operatorname{td}, 2 \mathrm{H}, J=7.8 \mathrm{~Hz}, J=1.5 \mathrm{~Hz}), 7.81(\mathrm{~s}, 2 \mathrm{H}), 7.52(\mathrm{~d}, 2 \mathrm{H}, J=5.5 \mathrm{~Hz}), 7.25(\mathrm{td}, 2 \mathrm{H}, J=$ $5.6 \mathrm{~Hz}, J=1.2 \mathrm{~Hz}), 7.23(\mathrm{~d}, 2 \mathrm{H}, J=5.6 \mathrm{~Hz}), 7.06(\mathrm{td}, 2 \mathrm{H}, J=5.6 \mathrm{~Hz}, J=1.3 \mathrm{~Hz}), 3.80$ (m, 4H), 2.26 (m, 4H). MALDI-TOF: $m / z 715.52$ (calculated for $\mathrm{C}_{34} \mathrm{H}_{28} \mathrm{BrN}_{7} \mathrm{Ru}$ (M$\left.2 \mathrm{PF}_{6}\right)^{+} 715.61$ ); $m / z 860.62$ (calculated for $\mathrm{C}_{34} \mathrm{H}_{28} \mathrm{BrF}_{6} \mathrm{~N}_{7} \mathrm{PRu}\left(\mathrm{M}-\mathrm{PF}_{6}\right)^{+}$860.57). 


\section{Ruthenium(II) (4'-bromo-2,2';6',2"'-terpyridine)(4,4',4',-tripyrrolidin-1-yl-}

2,2';6',2"-terpyridine) bix(hexafluorophosphate) (Pyr $\left.{ }_{3} \mathbf{R u B r}\right) .4,4$ ',4"-tripyrrolidin-1yl-2,2';6',2"'-terpyridine (Pyr ${ }_{3}$-tpy) $(62.6 \mathrm{mg}, 0.142 \mathrm{mmol})$ and ruthenium(III) (4'bromo-2,2';6',2”-terpyridyl) trichloride (8) $(74.5 \mathrm{mg}, 0.143 \mathrm{mmol})$ were combined in a $50 \mathrm{~mL}$ round bottom flask equipped with stirbar and condenser. Methanol (15 mL) was added and the flask was purged with argon gas for 20 minutes. N-ethyl morpholine $(0.02$ $\mathrm{mL}, \sim 1$ eqv.) was added and the mixture was refluxed under nitrogen for 2 hours, during which time the reaction mixture turned dark red in color. After this duration, the reaction mixture was cooled and the solvent was removed, leaving a brownish-red solid. This crude material was purified by chromatography on silica using 90:9:1 acetonitrile: water: saturated aqueous $\mathrm{KNO}_{3}$ solution as eluent. The first and third orange bands were identified as [ruthenium(II) bis(4,4',4”'-pyrrolidin-1-yl-2,2';6',2'-terpyridine) $]^{2+}$ and [ruthenium(II) bis(4'-bromo-2,2';6',2'-terpyridine) $]^{2+}$, respectively, while the middle band was identified as the desired product. This band was collected and concentrated on a rotary evaporator, and to this was added excess ammonium hexafluorophosphate. Water was added until a brownish-red precipitate formed, which was collected by filtration through a fritted funnel, then washed with water and ether to yield pure product (59.9 mg, 37\%). The side products were collected and worked up in similar fashion, for

later use. ${ }^{1} \mathrm{H}$ NMR $\left(500 \mathrm{MHz}, \mathrm{CD}_{3} \mathrm{CN}\right): \delta 8.86(\mathrm{~s}, 2 \mathrm{H}), 8.43(\mathrm{dt}, 2 \mathrm{H}, J=8.1 \mathrm{~Hz}, J=1.5$ $\mathrm{Hz}), 7.88(\mathrm{td}, 2 \mathrm{H}, J=7.6 \mathrm{~Hz}, J=1.5 \mathrm{~Hz}), 7.73(\mathrm{~s}, 2 \mathrm{H}), 7.54(\mathrm{dt}, 2 \mathrm{H}, J=5.6 \mathrm{~Hz}, J=0.7$ $\mathrm{Hz}), 7.40(\mathrm{~d}, 2 \mathrm{H}, J=2.7 \mathrm{~Hz}), 7.26(\mathrm{td}, 2 \mathrm{H}, J=5.6 \mathrm{~Hz}, J=1.1 \mathrm{~Hz}), 6.46(\mathrm{~d}, 2 \mathrm{H}, J=6.7$ Hz), $6.02(\mathrm{dd}, 2 \mathrm{H}, J=6.7 \mathrm{~Hz}, J=2.9 \mathrm{~Hz}), 3.80(\mathrm{~m}, 4 \mathrm{H}), 3.35($ br s, $4 \mathrm{H}), 2.24(\mathrm{~m}, 4 \mathrm{H})$, 
$1.96(\mathrm{~m}, 4 \mathrm{H})$. HRMS: $m / z=998.1476$ (calcd. for $\mathrm{C}_{42} \mathrm{H}_{42} \mathrm{BrF}_{6} \mathrm{~N}_{9} \mathrm{PRu}\left(\mathrm{M}-\mathrm{PF}_{6}\right)^{+}=$ 998.144).

\section{Osmium(II) (4'-bromo-2,2';6',2”-terpyridine)(2,2';6',2’'-terpyridine)}

bis(hexafluorophosphate) (OsBr). 2,2';6',2”-terpyridine (3) (280 mg, $1.2 \mathrm{mmol})$ and osmium(III) (4'-bromo-2,2';6',2”-terpyridyl) trichloride (9) (890 mg, 1.2 mmol) were combined in a $250 \mathrm{~mL}$ round bottom flask equipped with stirbar and condenser. Ethylene glycol $(50 \mathrm{~mL})$ was added and the mixture was refluxed under air for 2 hours, during which time the reaction mixture turned dark brown in color. After this duration, the reaction mixture was cooled and excess ammonium hexafluorophosphate was added, followed by water until a dark brown precipitate formed. This solid was collected by filtration on a fritted funnel, washed by water, taken up in acetonitrile, and evaporated to dryness. The crude solid was purified by chromatography on silica gel using 90:9:1 acetonitrile: water: saturated aqueous $\mathrm{KNO}_{3}$ solution as eluent. The first and third orange bands were identified as [osmium (II) bis(4'-bromo-2,2';6',2'-terpyridine) $]^{2+}$ and [osmium (II) bis(2,2';6',2'-terpyridine) $]^{2+}$, respectively, while the middle band was identified as the desired product. This band was collected and concentrated on a rotary evaporator, and to this was added excess ammonium hexafluorophosphate. Water was added until a brownish-red precipitate formed, which was collected by filtration through a fritted funnel, then washed with water and ether to yield pure product (340 mg, 27\%). The side products were collected and worked up in similar fashion, for later use. ${ }^{1} \mathrm{H}$ NMR (500 MHz, CD $\left.{ }_{3} \mathrm{CN}\right): \delta 8.99(\mathrm{~s}, 2 \mathrm{H}), 8.76(\mathrm{~d}, 2 \mathrm{H}, J=8.2 \mathrm{~Hz}), 8.46(\mathrm{~d}, 2 \mathrm{H}, J=8.2$ $\mathrm{Hz}), 7.96(\mathrm{t}, 2 \mathrm{H}, J=8.2 \mathrm{~Hz}), 7.79(\mathrm{~m}, 4 \mathrm{H}), 7.25(\mathrm{~d}, 2 \mathrm{H}, J=5.7 \mathrm{~Hz}), 7.22(\mathrm{~d}, 2 \mathrm{H}, J=5.8$ 
$\mathrm{Hz}), 7.10(\mathrm{~m}, 4 \mathrm{H}) . \operatorname{HRMS}\left(\mathrm{ESI}^{+}\right) \mathrm{m} / z=881.0282\left(\right.$ calcd for $\mathrm{C}_{30} \mathrm{H}_{21} \mathrm{~F}_{6} \mathrm{~N}_{6} \mathrm{BrOsP}(\mathrm{M}-$ $\left.\left.\mathrm{PF}_{6}\right)^{+}=881.0268\right)$

C. Porphyrin Precursors. The syntheses and characterization of starting materials [5-(triisopropylethynyl)-10,20-bis[2,6-bis(3,3-dimethyl-1butyloxy)phenyl)porphinato]zinc(II) (10), (5-bromo-15-(triisopropylethynyl)-10,20bis(2,6-bis(3,3-dimethyl-1-butyloxy)phenyl)porphinato]zinc(II) (11) and (5-ethynyl10,20-bis(2,6-bis(3,3-dimethyl-1-butyloxy)phenyl)porphinato]zinc(II) (EPZn, 13) have been reported in an earlier work. ${ }^{3}$ The synthesis of 1-[(5-,10,20-bis(2,6-bis(3,3-dimethyl1-butyloxy)phenyl)porphinato)zinc(II)]-2-[(5' -,15' -(ethynyl)-10',20'-bis(2,6-bis(3,3dimethyl-1-butyloxy)phenyl)porphinato)zinc(II)]-ethyne (EPZn 2,17$)$ from starting materials 10 and 11 is outlined in Scheme S4. Free-base 5-ethynyl-10,20-bis(2,6-bis(3,3dimethyl-1-butyloxy)phenyl)porphyrin (14) was used as an intermediate because direct synthesis of 1-[(5-,10,20-bis(2,6-bis(3,3-dimethyl-1-butyloxy)phenyl)porphinato)zinc(II)]-2-[(5'-,15'-(triisopropylsilylethynyl)-10',20'-bis(2,6-bis(3,3-dimethyl-1butyloxy)phenyl)porphinato)zinc(II)]-ethyne (16) via reaction of starting materials 11 and 13 (EPZn) results in a mixture of desired product 16 and a butadiyne-bridged side product that was difficult to separate via standard chromatographic techniques. Conversely, purification of $\mathbf{1 5}$ from the analogous zinc-free-base butadiyne-bridged side product resulting from the reaction of $\mathbf{1 3}$ and $\mathbf{1 4}$ was easily achieved using standard column chromatography and a coordinating solvent (THF) as the eluent. Zinc-free-base dimer $\mathbf{1 5}$ is then easily converted to the zinc-zinc dimer $\mathbf{1 6}$ in high yield via a standard metal-insertion reaction. 


\section{5-triisopropylethynyl-10,20-bis(2,6-bis(3,3-dimethyl-1-butyloxy)phenyl)-}

porphyrin (12). In a $500 \mathrm{~mL}$ round bottom flask equipped with stirbar was dissolved 10 (800 mg, $0.723 \mathrm{mmol})$ in chloroform $(250 \mathrm{~mL})$. Trifluoroacetic acid $(\sim \mathrm{mL})$ was added, after which the reaction mixture changed from purple to dark green. The reaction was stirred 10 minutes at room temperature, at which time the starting material was consumed as shown by thin layer chromatography (15\% THF in hexanes as eluent). Additionally, electronic absorption spectroscopy (UV/Vis) of the reaction mixture shows that demetallation has occurred. Saturated aqueous sodium bicarbonate solution $(\sim 150 \mathrm{~mL})$ was added to neutralize the excess acid, and the reaction stirred an additional 10 minutes, which caused the reaction mixture to gradually change back to a purple color. The aqueous layer was separated off in a separation funnel, and the organic phase was washed twice more with bicarbonate solution, followed by two washes with distilled water. The organic phase was collected, dried over sodium sulfate, filtered and concentrated to dryness in vacuo. The crude product was purified on silica using $15 \%$ THF in hexanes as eluent, followed by a second column using $40 \%$ chloroform in hexanes as eluent. The desired bands were isolated and concentrated to dryness by rotary evaporation to yield pure product (726 mg, 96\% yield). This compound was used immediately in the next procedure without further purification or characterization.

\section{5-ethynyl-10,20-bis(2,6-bis(3,3-dimethyl-1-butyloxy)phenyl)porphyrin (14).}

In a $100 \mathrm{~mL}$ round bottom flask was charged $12(400 \mathrm{mg}, 0.383 \mathrm{mmol})$ and freshly opened HPLC grade THF $(\sim 30 \mathrm{~mL})$. The flask was purged with argon gas for twenty minutes, following which tetrabutylammonium fluoride $(0.4 \mathrm{~mL}, 0.1 \mathrm{M}$ solution in THF, $0.402 \mathrm{mmol}$ ) was added. The reaction was stirred for 5 minutes, at which time the 
starting material had been consumed as shown by thin layer chromatography $(30 \%$ chloroform in hexanes as eluent). The reaction was stirred for an additional 2-3 minutes to assure completion, and then $\sim 2 \mathrm{~mL}$ water was added. The mixture was then purified immediately by flash chromatography on silica gel using neat chloroform as eluent. The major band was collected and concentrated to dryness in vacuo to yield pure product (335 mg, 99\% yield). ${ }^{1} \mathrm{H}$ NMR (500 MHz, $\left.\mathrm{CDCl}_{3}\right): \delta 10.02(\mathrm{~s}, 1 \mathrm{H}), 9.62(\mathrm{~d}, 2 \mathrm{H}, J=4.6 \mathrm{~Hz})$, $9.15(\mathrm{~d}, 2 \mathrm{H}, J=4.5 \mathrm{~Hz}), 8.86(\mathrm{~d}, 2 \mathrm{H}, J=4.7 \mathrm{~Hz}), 8.82(\mathrm{~d}, 2 \mathrm{H}, J=4.5 \mathrm{~Hz}), 7.70(\mathrm{t}, 2 \mathrm{H}, J$ $=8.4 \mathrm{~Hz}), 7.00(\mathrm{~d}, 4 \mathrm{H}, J=8.6 \mathrm{~Hz}), 4.11(\mathrm{~s}, 1 \mathrm{H}), 3.89(\mathrm{t}, 8 \mathrm{H}, J=7.2 \mathrm{~Hz}), 0.85(\mathrm{t}, 8 \mathrm{H}, J$ $=7.4 \mathrm{~Hz}), 0.27(\mathrm{~s}, 36 \mathrm{H}),-2.61(\mathrm{~s}, 2 \mathrm{H})$.

1-[5-,10,20-bis(2,6-bis(3,3-dimethyl-1-butyloxy)phenyl)porphyrin]-2-[(5'-,15'(triisopropylsilylethynyl)-10',20'-bis(2,6-bis(3,3-dimethyl-1-butyloxy)phenyl)porphinato)zinc(II)]-ethyne (15). A $250 \mathrm{~mL}$ round bottom flask equipped with stirbar was charged with 12 (504 mg, $0.568 \mathrm{mmol})$ and $14(674 \mathrm{mg}, 0.568 \mathrm{mmol}) . \mathrm{Pd}_{2}\left(\mathrm{dba}_{3}\right)(78$ $\mathrm{mg}, 0.085 \mathrm{mmol})$ and $\mathrm{AsPh}_{3}(210 \mathrm{mg}, 0.68 \mathrm{mmol})$ were added in a dry box and the flask was sealed with a septum. To these solids was added approximately $75 \mathrm{~mL}$ of a deoxygenated 5:1 mixture of THF:triethylamine via cannula and this mixture was heated at $60{ }^{\circ} \mathrm{C}$ for 16 hours, or until the starting materials were consumed as shown by thin layer chromatography (15\% THF in hexanes as eluent). The reaction was then cooled and concentrated to about $40 \%$ of the initial volume, whereupon it was taken up in ethyl acetate and washed three times with aqueous ammonium chloride solution and then three times with water. The organic phase was collected, dried over sodium sulfate and then filtered. The filtrate was evaporated to dryness. This crude material was then chromatographed on a medium-sized silica gel using 20\% THF in hexanes as the eluent. 
The fastest band (brown green) which constituted a majority of the material was isolated from a slower moving impurity (dark green) which was identified as the homo-coupled butadiyne-bridged porphyrin side product. The desired fractions were collected and concentrated to dryness in vacuo, whereupon this mixture was further purified by sizeexclusion chromatography (SX-1 biobeads in THF as eluent) to remove monomeric contaminants. The product band was isolated, concentrated to dryness in vacuo and chromatographed one more time on silica using $20 \%$ THF in hexanes as eluent to remove a residual butadiyne-bridged porphyrin impurity. The desired band was collected and evaporated to dryness to yield pure product (590 mg, 52\%). ${ }^{1} \mathrm{H}$ NMR (500 MHz, $\left.\mathrm{CDCl}_{3}\right): \delta 10.31(\mathrm{~d}, 2 \mathrm{H}, J=4.6 \mathrm{~Hz}), 10.29(\mathrm{~d}, 2 \mathrm{H}, J=4.5 \mathrm{~Hz}), 9.99(\mathrm{~s}, 1 \mathrm{H}), 9.65(\mathrm{~d}, 2 \mathrm{H}$, $J=4.5 \mathrm{~Hz}), 9.15(\mathrm{~d}, 2 \mathrm{H}, J=4.6 \mathrm{~Hz}), 9.00(\mathrm{~d}, 2 \mathrm{H}, J=4.5 \mathrm{~Hz}), 8.99(\mathrm{~d}, 2 \mathrm{H}, J=4.5 \mathrm{~Hz})$, $8.86(\mathrm{~d}, 4 \mathrm{H}, J=4.5 \mathrm{~Hz}), 7.70(\mathrm{~m}, 4 \mathrm{H}), 7.02(\mathrm{~m}, 4 \mathrm{H}), 3.39(\mathrm{~m}, 16 \mathrm{H}), 1.46(\mathrm{~m}, 21 \mathrm{H}), 0.89$ $(\mathrm{m}, 16 \mathrm{H}), 0.29(\mathrm{~s}, 72 \mathrm{H}),-2.19(\mathrm{~s}, 2 \mathrm{H})$. MALDI-TOF: $m / z$ 1989.36 (calculated for $\mathrm{C}_{125} \mathrm{H}_{156} \mathrm{~N}_{8} \mathrm{O}_{8} \mathrm{SiZn}(\mathrm{M})^{+}$1989.11).

\section{1-[(5-,10,20-bis(2,6-bis(3,3-dimethyl-1-butyloxy)phenyl)porphinato)zinc(II)]-}

\section{2-[(5'-,15'-(triisopropylsilylethynyl)-10',20'-bis(2,6-bis(3,3-dimethyl-1-butyloxy)-} phenyl)porphinato)zinc(II)]-ethyne (16). A $250 \mathrm{~mL}$ round bottom flask equipped with stirbar and condenser was charged with 15 (240 mg, $0.120 \mathrm{mmol})$ and zinc acetate dehydrate $(40 \mathrm{mg}, 0.180 \mathrm{mmol})$ and $100 \mathrm{~mL}$ chloroform. This mixture was refluxed for approximately 1 hour, at which point the reaction was finished as shown by electronic absorption spectroscopy. The mixture was refluxed an additional 30 minutes, cooled to room temperature, concentrated in vacuo, washed twice with aqueous ammonium chloride solution and then twice with water. The chloroform layer was isolated and dried 
of sodium sulfate and filtered. The filtrate was concentrated to dryness and the resulting crude material was purified by column chromatography utilizing silica gel and $15 \% \mathrm{THF}$ in hexanes as eluent. The product eluted as an olive green band, which was collected and concentrated to dryness to yield pure product (236 mg, 95\%). ${ }^{1} \mathrm{H}$ NMR (500 MHz, $\left.\mathrm{CDCl}_{3}\right): \delta 10.40(\mathrm{~d}, 2 \mathrm{H}, J=4.5 \mathrm{~Hz}), 10.35(\mathrm{~d}, 2 \mathrm{H}, J=4.4 \mathrm{~Hz}), 10.14$ (br s, $\left.1 \mathrm{H}\right), 9.66(\mathrm{~d}$, $2 \mathrm{H}, J=4.4 \mathrm{~Hz}), 9.25(\mathrm{~d}, 2 \mathrm{H}, J=4.5 \mathrm{~Hz}), 9.12(\mathrm{~d}, 2 \mathrm{H}, J=4.4 \mathrm{~Hz}), 9.01(\mathrm{~d}, 2 \mathrm{H}, J=4.5$ $\mathrm{Hz}), 8.97(\mathrm{~d}, 2 \mathrm{H}, J=4.4 \mathrm{~Hz}), 8.87(\mathrm{~d}, 2 \mathrm{H}, J=4.5 \mathrm{~Hz}), 7.74(\mathrm{t}, 2 \mathrm{H}, J=8.4 \mathrm{~Hz}), 7.72(\mathrm{t}$, $2 \mathrm{H}, J=8.5 \mathrm{~Hz}), 7.06(\mathrm{~m}, 8 \mathrm{H}), 3.97(\mathrm{~m}, 16 \mathrm{H}), 1.45(\mathrm{~m}, 21 \mathrm{H}), 0.88(\mathrm{~m}, 16 \mathrm{H}), 0.33(\mathrm{~s}$, 36H), 0.28 (s, 36H). MALDI-TOF: $m / z 2052.48$ (calculated for $\mathrm{C}_{125} \mathrm{H}_{154} \mathrm{~N}_{8} \mathrm{O}_{8} \mathrm{SiZn}_{2}(\mathrm{M})^{+}$ 2051.02).

\section{1-[(5-,10,20-bis(2,6-bis(3,3-dimethyl-1-butyloxy)phenyl)porphinato)zinc(II)]-} 2-[(5'-,15'-(ethynyl)-10',20'-bis(2,6-bis(3,3-dimethyl-1-butyloxy)phenyl)porphinato)zinc(II)]-ethyne (EPZn 2,17$)$. A $100 \mathrm{~mL}$ round bottom flask was equipped with a stirbar and charged with $16(100 \mathrm{mg}, 0.049 \mathrm{mmol})$ and $30 \mathrm{~mL}$ THF. Tetrabutylammonium fluoride $(0.1 \mathrm{M}$ solution in THF, $0.6 \mathrm{~mL}, 0.063 \mathrm{mmol})$ was added and the reaction was stirred until the starting material was consumed as shown by thin layer chromatography (15\% THF in hexanes as eluent), about 10-15 minutes. The reaction mixture was concentrated to about $20 \%$ total volume and then immediately chromatographed on a medium silica gel column using 20\% THF in hexanes as eluent. A minor trailing band identified as residual starting material was separated from the major fast-moving band, which was collected and concentrated to dryness in vacuo to yield the desired product (90 $\mathrm{mg}, 96 \%$ ). This product was used immediately or stored in the dark in the freezer to prevent decomposition. ${ }^{1} \mathrm{H}$ NMR $\left(500 \mathrm{MHz}, \mathrm{CDCl}_{3}\right): \delta 10.39(\mathrm{~d}, 2 \mathrm{H}, J=4.4 \mathrm{~Hz}), 10.34$ 
(d, 2H, $J=4.4 \mathrm{~Hz}), 9.99(\mathrm{~s}, 1 \mathrm{H}), 9.57(\mathrm{~d}, 2 \mathrm{H}, J=4.4 \mathrm{~Hz}), 9.19$ (d, 2H, $J=4.2 \mathrm{~Hz}), 9.06$

$(\mathrm{d}, 2 \mathrm{H}, J=4.4 \mathrm{~Hz}), 8.95(\mathrm{~d}, 2 \mathrm{H}, J=4.5 \mathrm{~Hz}), 8.90(\mathrm{~d}, 2 \mathrm{H}, J=4.4 \mathrm{~Hz}), 8.83(\mathrm{~d}, 2 \mathrm{H}, J=$

$4.4 \mathrm{~Hz}), 7.72(\mathrm{t}, 2 \mathrm{H}, J=8.5 \mathrm{~Hz}), 7.71(\mathrm{t}, 2 \mathrm{H}, J=8.5 \mathrm{~Hz}), 7.00(\mathrm{~m}, 8 \mathrm{H}), 4.10(\mathrm{~s}, 1 \mathrm{H})$,

$3.93(\mathrm{t} 8 \mathrm{H}, J=7.5 \mathrm{~Hz}), 3.83(\mathrm{t}, 8 \mathrm{H}, \mathrm{J}=6.7 \mathrm{~Hz}), 0.85(\mathrm{~m}, 16 \mathrm{H}), 0.38(\mathrm{~s}, 36 \mathrm{H}), 0.34(\mathrm{~s}$,

36H). MALDI-TOF: $m / z 1901.18$ (calculated for $\mathrm{C}_{116} \mathrm{H}_{134} \mathrm{~N}_{8} \mathrm{O}_{8} \mathrm{Zn}_{2}(\mathrm{M})^{+}$1899.13).

\section{PZn-tpy and PZn -tpy Benchmarks. The PZn-tpy and PZn $\mathbf{n}_{2}$-tpy}

benchmarks were synthesized via metal-mediated cross-coupling of the 4'-bromo-

2,2';6',2"-terpyridine (brtpy) with the appropriate ethynylated-porphyrin precursor (i.e.,

13 or $\mathbf{1 7}$ for PZn-tpy and PZn -tpy, respectively), as outlined in Scheme S5.

[5-(4'-ethynyl-2,2’;6',2’'-terpyridyl)-10,20-bis(2,6-bis(3,3-dimethyl-1-

butyloxy)phenyl)porphinato]zinc(II) (PZn-tpy). 13 (EPZn)(155 mg, 0.016 mmol),

brtpy $(280 \mathrm{mg}, 0.9 \mathrm{mmol})$, diisopropylamine $(8 \mathrm{~mL})$, and THF $(30 \mathrm{~mL})$ were brought together in an oven-dried $100 \mathrm{~mL}$ Schlenk tube. The solution was degassed, following which $\mathrm{Pd}\left(\mathrm{PPh}_{3}\right)_{4}(30 \mathrm{mg}, 0.026 \mathrm{mmol})$ and $\mathrm{CuI}(8 \mathrm{mg}, 0.042 \mathrm{mmol})$ were added. The reaction was stirred under nitrogen at $70{ }^{\circ} \mathrm{C}$ for 20 hours, cooled to room temperature, and evaporated. The product was purified by column chromatography on neutral alumina using 3:2 hexanes:THF as eluent. The product eluted as a green band; the volatiles were evaporated and the residual solid was further purified on a size exclusion column (SX-1 biobeads) utilizing THF as eluent. A second round of chromatography on neutral alumina using 1:1 THF:hexanes as the eluent gave pure compound $(96 \mathrm{mg}, 51 \%) .{ }^{1} \mathrm{H}$ NMR (250 MHZ, pyridine- $\left.d_{5}\right): \delta 10.14(\mathrm{~s}, 1 \mathrm{H}), 10.08(\mathrm{~d}, 2 \mathrm{H}, J=4.5 \mathrm{~Hz}), 9.36(\mathrm{~d}, 2 \mathrm{H}, J$ $=4.6 \mathrm{~Hz}), 9.34(\mathrm{~d}, 2 \mathrm{H}, J=4.5 \mathrm{~Hz}), 9.31(\mathrm{~s}, 2 \mathrm{H}), 9.36(\mathrm{~d}, 2 \mathrm{H}, J=4.4 \mathrm{~Hz}), 8.89(\mathrm{~m}, 4 \mathrm{H})$, $8.06(\mathrm{t}, 2 \mathrm{H}, J=8.3 \mathrm{~Hz}), 7.94(\mathrm{dt}, 2 \mathrm{H}, J=7.7 \mathrm{~Hz}, J=1.9 \mathrm{~Hz}), 7.38(\mathrm{~m}, 6 \mathrm{H}), 4.13(\mathrm{t}, 8 \mathrm{H}$, 
$J=7.1 \mathrm{~Hz}), 0.93(\mathrm{t}, 8 \mathrm{H}, J=7.5 \mathrm{~Hz}), 0.33(\mathrm{~s}, 36 \mathrm{H})$. MS (MALDI-TOF): $m / z 1181.13$

(calculated for $\mathrm{C}_{73} \mathrm{H}_{77} \mathrm{~N}_{7} \mathrm{O}_{4} \mathrm{Zn}(\mathrm{M})^{+}$1181.83).

1-[(5-,10,20-bis(2,6-bis(3,3-dimethyl-1-butyloxy)phenyl)porphinato)zinc(II)]2-[(5'-,15'-(4"'-ethynyl-2",2'";6",,2"',-terpyridyl)-10',20'-bis(2,6-bis(3,3-dimethyl-1butyloxy)phenyl)porphinato)zinc(II)]-ethyne (PZn with stir-bar was added EPZn 2 (17) (30 mg, $0.0158 \mathrm{mmol})$ and Brtpy (14.8 mg, 0.0474 mmol). $\mathrm{Pd}_{2} \mathrm{dba}_{3}(3.6 \mathrm{mg}, 0.00395 \mathrm{mmol})$ and $\mathrm{P}(\mathrm{o}-\mathrm{tol})_{3}(7.2 \mathrm{mg}, 0.0237 \mathrm{mmol})$ were then added in a dry box and the tube was sealed with a septum. Approximately $2 \mathrm{~mL}$ of a 10:1 THF:triethylamine solvent mixture (degassed by three consecutive freeze-pumpthaw cycles) was added to the reactants via syringe and the reaction mixture was stirred under Argon at $60{ }^{\circ} \mathrm{C}$ for 16 hours. The reaction mixture was then cooled and concentrated to dryness by rotary evacuation. The crude mixture was purified on a medium-length silica gel column using 1:1 THF:hexanes as eluent. The desired product eluted second following residual 17 starting material. The product fraction was collected and further purified by size exclusion chromatography (SX-1 biobeads, THF as eluent) and finally by flash chromatography on silica gel using 1:1 THF:hexanes as eluent. The product band was collected and concentrated to dryness to yield pure product (26 mg, 77\% yield). ${ }^{1} \mathrm{H}$ NMR (500 MHZ, $\left.\mathrm{CDCl}_{3}\right): \delta 10.40(\mathrm{~d}, 2 \mathrm{H}, J=4.5 \mathrm{~Hz}), 10.35(\mathrm{~d}, 2 \mathrm{H}, J=$ $4.5 \mathrm{~Hz}), 10.05(\mathrm{~s}, 1 \mathrm{H}), 9.78(\mathrm{~d}, 2 \mathrm{H}, J=4.5 \mathrm{~Hz}), 9.23(\mathrm{~d}, 2 \mathrm{H}, J=4.4 \mathrm{~Hz}), 9.10$ (d, 2H, $J$ $=4.5 \mathrm{~Hz}), 9.04(\mathrm{~s}, 2 \mathrm{H}), 8.99(\mathrm{~d}, 2 \mathrm{H}, J=4.5 \mathrm{~Hz}), 8.95(\mathrm{~d}, 2 \mathrm{H}, J=4.4 \mathrm{~Hz}), 8.93(\mathrm{~d}, 2 \mathrm{H}, J$ $=4.4 \mathrm{~Hz}), 8.84(\mathrm{~d}, 2 \mathrm{H}, J=4.4 \mathrm{~Hz}), 8.74(\mathrm{~d}, 2 \mathrm{H}, J=7.8 \mathrm{~Hz}), 7.95(\mathrm{td}, 2 \mathrm{H}, J=7.6 \mathrm{~Hz}, J=$ $1.7 \mathrm{~Hz}), 7.73(\mathrm{t}, 2 \mathrm{H}, J=8.9 \mathrm{~Hz}), 7.72(\mathrm{t}, 2 \mathrm{H}, 4$-phenyl H, $J=8.9 \mathrm{~Hz}), 7.41$ (t, 2H, $J=$ $6.8 \mathrm{~Hz}), 7.04(\mathrm{~d}, 8 \mathrm{H}, J=7.7 \mathrm{~Hz}), 3.97(\mathrm{t}, 8 \mathrm{H}, J=7.3 \mathrm{~Hz}), 3.96(\mathrm{t}, 8 \mathrm{H}, J=7.4 \mathrm{~Hz}), 0.94$ 
$(\mathrm{t}, 8 \mathrm{H}, J=7.3 \mathrm{~Hz}), 0.89(\mathrm{t}, 8 \mathrm{H}, J=7.4 \mathrm{~Hz}), 0.33(\mathrm{~s}, 36 \mathrm{H}), 0.27(\mathrm{~s}, 36 \mathrm{H})$. MALDI-TOF:

$m / z 2128.03$ (calculated for $\mathrm{C}_{131} \mathrm{H}_{143} \mathrm{~N}_{11} \mathrm{O}_{8} \mathrm{Zn}_{2}(\mathrm{M})^{+}$2130.39).

E. Oligo(Porphinato)Zinc-(Polypyridyl)Metal(II) Supermolecules. The syntheses of ruthenium(II) [5-(4'-ethynyl-(2,2';6',2"'-terpyridinyl))-10,20-bis(2,6-bis(3,3dimethyl-1-butyloxy)phenyl)-porphinato)zinc(II)][2,2';6',2"'-terpyridine] bis(hexafluorophosphate) (RuPZn) and osmium(II) [5-(4'-ethynyl-(2,2';6',2'-terpyridinyl))-10,20bis(2,6-bis(3,3-dimethyl-1-butyloxy)phenyl)porphinato)zinc(II)]-[2,2';6',2”-terpyridine] bis(hexafluorophosphate) (OsPZn), have been reported previously. ${ }^{3}$.(ref) The syntheses of ruthenium(II) [5-(4'-ethynyl-(2,2';6',2”-terpyridinyl))-10,20-bis(2,6-bis(3,3-dimethyl1-butyloxy)phenyl)porphinato)zinc(II)][4'-pyrrolidin-1-yl-2,2';6',2”-terpyridine] bis(hexafluorophosphate) (Pyr $\mathbf{1}_{1} \mathbf{R u P Z n ) , ~ R u t h e n i u m ( I I ) ~ [ 5 - ( 4 ' - e t h y n y l - ( 2 , 2 ' ; 6 ' , 2 ” - ~}$ terpyridinyl))-10,20-bis(2,6-bis(3,3-dimethyl-1-butyloxy)phenyl)porphinato)zinc(II)][4,4',4"'-pyrrolidin-1-yl-2,2';6',2"'-terpyridine] bis(hexafluoro-phosphate) (Pyr $\mathbf{P}_{3} \mathbf{R u P Z n ) ,}$ ruthenium(II) [5-(4'-ethynyl-(2,2';6',2”-terpyridinyl))-15-[(5'”-,10'”,20'”'-bis(2,6bis(3,3-dimethyl-1-butyloxy)phenyl)porphinato)zinc(II)]-10,20-bis(2,6-bis(3,3-dimethyl1-butyloxy)phenyl)porphinato)zinc(II)][2,2';6',2"-terpyridine] bis(hexafluorophosphate) (RuPZn $)$, ruthenium(II) [5-(4'-ethynyl-(2,2';6',2"-terpyridinyl))-15-[(5'”-,10'”,20’”bis(2,6-bis(3,3-dimethyl-1-butyloxy)phenyl)porphinato)zinc(II)]-10,20-bis(2,6-bis(3,3dimethyl-1-butyloxy)phenyl)porphinato)zinc(II)][4'-pyrrolidin-1-yl-2,2';6',2”terpyridine] bis(hexafluorophosphate) $\left(\mathbf{P y r}_{\mathbf{1}} \mathbf{R u P Z n _ { 2 }}\right)$, ruthenium(II) [5-(4'-ethynyl(2,2';6',2"-terpyridinyl))-15-[(5'"-,10"',20"'-bis(2,6-bis(3,3-dimethyl-1-butyloxy)phenyl)porphinato)zinc(II)]-10,20-bis(2,6-bis(3,3-dimethyl-1-butyloxy)phenyl)porphinato)zinc(II)][4,4',4”-pyrrolidin-1-yl-2,2';6',2”-terpyridine] bis(hexafluoro- 
phosphate) (Pyr $\mathbf{3} \mathbf{R u P Z n}$ ), and osmium (II) [5-(4'-ethynyl-(2,2';6',2”-terpyridinyl))-15[(5'"-,10"',20'"'-bis(2,6-bis(3,3-dimethyl-1-butyloxy)phenyl)porphinato)zinc(II)]-10,20bis(2,6-bis(3,3-dimethyl-1-butyloxy)phenyl)porphinato)zinc(II)][2,2';6',2’-terpyridine] bis(hexafluorophosphate) (OSPZn $\mathbf{P})$ from the appropriate halogenated metal(II) bis(terpyridyl) (OsBr, RuBr, $\mathbf{P y r}_{1} \mathbf{R u B r}$ or $\mathbf{P y r}_{3} \mathbf{R u B r}$ ) and ethynyl-substituted porphyrinic (EPZn (13) or EPZn 2 (17)) precursor materials is depicted in Scheme 2.

General Procedure for the Preparation of $\mathrm{Pyr}_{1} R u P Z n$ and $\mathrm{Pyr}_{3} R u P Z n$. One equivalent each of EPZn and of $\mathbf{P y r}_{\mathbf{m}} \mathbf{R u B r}(\mathrm{m}=1,3)$ were placed in an appropriately sized Schlenk flask equipped with a stir bar. $\mathrm{Pd}_{2}(\mathrm{dba})_{3}(0.15 \mathrm{~mol} \%)$ and $\mathrm{AsPh}_{3}$ (2 eq.) were added under nitrogen atmosphere. A solvent mixture consisting of HPLC grade 6:3:1 MeCN:THF:triethylamine was degassed by a stream of dry nitrogen for approximately $30 \mathrm{~min}$. Enough of this solvent mixture to completely dissolve all reactants was added to the reaction vessel via cannula, and the resulting solution was heated to $60{ }^{\circ} \mathrm{C}$ for approximately $8 \mathrm{~h}$; consumption of starting materials was verified by thin layer chromatography (90:9:1 $\mathrm{MeCN}: \mathrm{H}_{2} \mathrm{O}$ :saturated aq. $\mathrm{KNO}_{3}$ as eluent) of the reaction mixture. The solution was then cooled to room temperature and evaporated. The crude product was purified by column chromatography using 90:9:1 MeCN: $\mathrm{H}_{2} \mathrm{O}:$ sat. aq. $\mathrm{KNO}_{3}$ as eluent; the product eluted second, following a small quantity of fast-moving homocoupled butadiyne-bridged bis[(porphinato)zinc(II)] side-product. The product fractions was concentrated, but not to dryness. Excess ammonium hexafluorophosphate was added, followed by enough water to cause the precipitation of a dark brown-green solid, which was isolated by filtration, and washed successively with water and diethyl 
ether. Additional column chromatography was performed if the level of purity was unsatisfactory as assessed by NMR spectroscopy.

Ruthenium(II) [5-(4'-ethynyl-(2,2';6',2'-terpyridinyl))-10,20-bis(2,6-bis(3,3dimethyl-1-butyloxy)phenyl)porphinato)zinc(II)][4'-pyrrolidin-1-yl-2,2';6',2'terpyridine] bis(hexafluorophosphate) (Pyr $\left.\mathbf{P}_{1} \mathbf{R u P Z n}\right)$. Reaction of EPZn (14.2 mg, $0.0149 \mathrm{mmol}), \mathbf{P y r}_{1} \mathbf{R u B r}(15.0 \mathrm{mg}, 0.0149 \mathrm{mmol}), \mathrm{Pd}_{2}(\mathrm{dba})_{3}(2.1 \mathrm{mg}, 0.00224 \mathrm{mmol})$, and $\mathrm{AsPh}_{3}(9.0 \mathrm{mg}, 0.030 \mathrm{mmol})$ in $7 \mathrm{~mL}$ 6:3:1 MeCN:THF:triethylamine under conditions outlined in the above procedure gave $20 \mathrm{mg} \mathbf{P y r}_{\mathbf{1}} \mathbf{R u P Z n}$ (71\% yield based on the EPZn starting material) after purification. ${ }^{1} \mathrm{H}$ NMR (500 MHZ, $\left.\mathrm{CD}_{3} \mathrm{CN}\right): \delta 10.16$ (s, 1H), $10.01(\mathrm{~d}, 2 \mathrm{H}, J=4.5 \mathrm{~Hz}), 9.34(\mathrm{~s}, 2 \mathrm{H}), 9.30(\mathrm{~d}, 2 \mathrm{H}, J=4.4 \mathrm{~Hz}), 9.02(\mathrm{~d}, 2 \mathrm{H}, J=$ $4.5 \mathrm{~Hz}), 8.84(\mathrm{~d}, 2 \mathrm{H}, J=4.5 \mathrm{~Hz}), 8.78(\mathrm{~d}, 2 \mathrm{H}, J=8.0 \mathrm{~Hz}), 8.50(\mathrm{~d}, 2 \mathrm{H}, J=8.1 \mathrm{~Hz}), 8.04$ $(\mathrm{td}, 2 \mathrm{H}, J=7.8 \mathrm{~Hz}, J=1.3 \mathrm{~Hz}), 7.89(\mathrm{td}, 2 \mathrm{H}, J=7.7 \mathrm{~Hz}, J=1.4 \mathrm{~Hz}), 7.86(\mathrm{~s}, 2 \mathrm{H}), 7.82$ $(\mathrm{t}, 2 \mathrm{H}, J=8.6 \mathrm{~Hz}), 7.59(\mathrm{~d}, 2 \mathrm{H}, J=5.0 \mathrm{~Hz}), 7.44(\mathrm{~d}, 2 \mathrm{H}, J=5.0 \mathrm{~Hz}), 7.31(\mathrm{td}, 2 \mathrm{H}, J=$ $7.6 \mathrm{~Hz}, J=1.5 \mathrm{~Hz}), 7.18(\mathrm{~d}, 4 \mathrm{H}, J=8.5 \mathrm{~Hz}), 7.12(\mathrm{td}, 2 \mathrm{H}, J=7.3 \mathrm{~Hz}, J=1.3 \mathrm{~Hz}), 4.00$ $(\mathrm{t}, 8 \mathrm{H}, J=7.1 \mathrm{~Hz}), 3.83(\mathrm{~m}, 4 \mathrm{H}), 2.28(\mathrm{~m}, 4 \mathrm{H}), 0.18(\mathrm{~s}, 36 \mathrm{H})$. MALDI-TOF: $m / z$ 1585.79 (calculated for $\mathrm{C}_{92} \mathrm{H}_{95} \mathrm{~N}_{11} \mathrm{O}_{4} \mathrm{RuZn}\left(\mathrm{M}-2 \mathrm{PF}_{6}\right)^{+}$1585.27); $\mathrm{m} / z 1730.08$ (calculated for $\mathrm{C}_{92} \mathrm{H}_{95} \mathrm{~F}_{6} \mathrm{~N}_{11} \mathrm{O}_{4} \mathrm{PRuZn}\left(\mathrm{M}-\mathrm{PF}_{6}\right)^{+}$1730.23).

Ruthenium(II) [5-(4'-ethynyl-(2,2';6',2'’-terpyridinyl))-10,20-bis(2,6-bis(3,3dimethyl-1-butyloxy)phenyl)porphinato)zinc(II)][4,4',4'’-pyrrolidin-1-yl-2,2';6',2”-

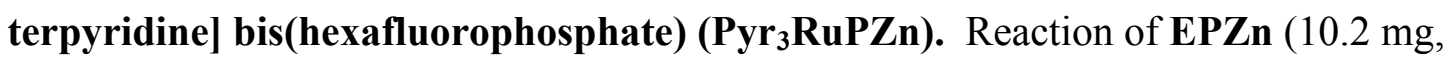
$0.0108 \mathrm{mmol}), \mathbf{P y r}_{3} \mathbf{R u B r}(12.3 \mathrm{mg}, 0.0123 \mathrm{mmol}), \mathrm{Pd}_{2}(\mathrm{dba})_{3}(1.5 \mathrm{mg}, 0.00161 \mathrm{mmol})$,

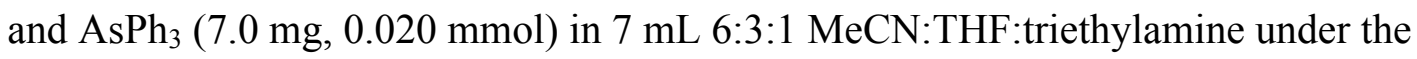
conditions outlined in the above procedure gave $12 \mathrm{mg} \mathbf{P y r}_{3} \mathbf{R u P Z n}$ (55\% yield based on 
the EPZn starting material) after purification. ${ }^{1} \mathrm{H}$ NMR $\left(500 \mathrm{MHZ}, \mathrm{CD}_{3} \mathrm{CN}\right): \delta 10.15$ (s, 1H), $10.00(\mathrm{~d}, 2 \mathrm{H}, J=4.5 \mathrm{~Hz}), 9.30(\mathrm{~d}, 2 \mathrm{H}, J=4.4 \mathrm{~Hz}), 9.29(\mathrm{~s}, 2 \mathrm{H}), 9.01$ (d, 2H, $J=$ $4.5 \mathrm{~Hz}), 8.84(\mathrm{~d}, 2 \mathrm{H}, J=4.4 \mathrm{~Hz}), 8.74(\mathrm{~d}, 2 \mathrm{H}, J=8.2 \mathrm{~Hz}), 7.98(\mathrm{t}, 2 \mathrm{H}, J=7.7 \mathrm{~Hz}), 7.83$ (t, 2H, $J=8.6 \mathrm{~Hz}), 7.79(\mathrm{~s}, 2 \mathrm{H}), 7.61(\mathrm{t}, 2 \mathrm{H}, J=5.2 \mathrm{~Hz}), 7.45(\mathrm{~d}, 2 \mathrm{H}, J=2.6 \mathrm{~Hz}), 7.31$ $(\mathrm{t}, 2 \mathrm{H}, J=5.7 \mathrm{~Hz}), 7.19(\mathrm{~d}, 4 \mathrm{H}, J=8.6 \mathrm{~Hz}), 6.67(\mathrm{~d}, 4 \mathrm{H}, J=6.8 \mathrm{~Hz}), 6.09(\mathrm{~d}, 2 \mathrm{H}, J=$ $5.2 \mathrm{~Hz}), 4.02(\mathrm{t}, 8 \mathrm{H}, J=7.1 \mathrm{~Hz}), 3.84(\mathrm{~m}, 4 \mathrm{H}), 3.38(\mathrm{br} \mathrm{s}, 4 \mathrm{H}), 2.28(\mathrm{~m}, 4 \mathrm{H}), 1.96(\mathrm{~m}$, 4H), $0.80(\mathrm{t}, 8 \mathrm{H}, J=7.1 \mathrm{~Hz}), 0.19(\mathrm{~s}, 36 \mathrm{H})$. MALDI-TOF: $m / z 1723.67$ (calculated for $\mathrm{C}_{100} \mathrm{H}_{109} \mathrm{~N}_{13} \mathrm{O}_{4} \mathrm{RuZn}\left(\mathrm{M}-2 \mathrm{PF}_{6}\right)^{+}$1723.48); $m / z 1868.78$ (calculated for $\mathrm{C}_{100} \mathrm{H}_{109} \mathrm{~F}_{6} \mathrm{~N}_{13} \mathrm{O}_{4} \mathrm{PRuZn}\left(\mathrm{M}-\mathrm{PF}_{6}\right)^{+}$1868.44).

\section{General Procedure for the Preparation of $\mathrm{MPZn}_{2}$ and $\operatorname{Pyr}_{\mathrm{m}} \operatorname{RuPZn}_{2}(\mathrm{~m}=1$,} 3; bis(terpyridyl)metal(II) $=\mathbf{M}$; metal $=\mathbf{R u}$, Os). One eq. of $\mathbf{E P Z n _ { 2 }}$ and $\sim 1.2$ eq. of MBr or $\mathbf{P y r}_{\mathbf{m}} \mathbf{R u B r}(\mathrm{m}=1,3)$ were placed in an appropriately-sized Schlenk flask equipped with a stir bar. $\mathrm{Pd}_{2}(\mathrm{dba})_{3}(0.15 \mathrm{~mol} \%)$ and $\mathrm{AsPh}_{3}$ (2 eq.) were added under nitrogen atmosphere. A solvent mixture consisting of HPLC grade 6:3:1

MeCN:THF:triethylamine was degassed by a stream of dry nitrogen for approximately 30 min. Enough of this solvent mixture to completely dissolve all of the starting materials was added to the reaction vessel via cannula, and the resulting solution was heated on an oil bath at $60{ }^{\circ} \mathrm{C}$ for approximately $8 \mathrm{~h}$, or until the starting materials were consumed as evidenced by thin layer chromatographic (90:9:1 $\mathrm{MeCN}: \mathrm{H}_{2} \mathrm{O}$ :saturated aq $\mathrm{KNO}_{3}$ as eluent) analysis of the reaction mixture. The reaction mixture was then cooled to room temperature and concentrated to dryness by rotary evaporation. The crude product was purified by column chromatography using 90:9:1 $\mathrm{MeCN}: \mathrm{H}_{2} \mathrm{O}$ :sat. aq. $\mathrm{KNO}_{3}$ as eluent; the product eluted second, following a small quantity of an unidentified side product. 
The product fraction was concentrated, but not to dryness. Excess ammonium hexafluorophosphate was added, followed by enough water to cause the precipitation of a brown solid, which was isolated by filtration, and washed successively with water and diethyl ether. This solid was taken up in THF and further purified by size-exclusion chromatography (SX-1 Biobeads) with THF as eluent, followed by flash chromatography on silica (90:9:1 MeCN: $\mathrm{H}_{2} \mathrm{O}$ :saturated aq $\mathrm{KNO}_{3}$ ). Counter ion metathesis using ammonium hexafluorophosphate (see above) gave the product as a brown solid. Additional column chromatography was performed if the level of purity was unsatisfactory as assessed by NMR spectroscopy.

\section{Ruthenium(II) [5-(4'-ethynyl-(2,2';6',2'-terpyridinyl))-15-[(5','-,10',,20'"'-}

bis(2,6-bis(3,3-dimethyl-1-butyloxy)phenyl)porphinato)zinc(II)]-10,20-bis(2,6bis(3,3-dimethyl-1-butyloxy)phenyl)porphinato)zinc(II)][2,2';6',2”-terpyridine] bis(hexafluorophosphate) (RuPZn $)$. Reaction of EPZn 2 (50.0 mg, $0.026 \mathrm{mmol})$, RuBr (34 mg, $0.037 \mathrm{mmol}), \mathrm{Pd}_{2}(\mathrm{dba})_{3}(4.8 \mathrm{mg}, 0.0053 \mathrm{mmol})$, and $\mathrm{AsPh}_{3}(16.1 \mathrm{mg}$,

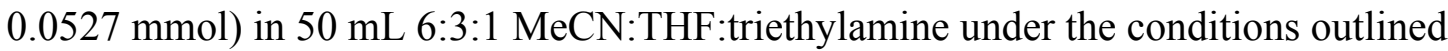
above gave 53 mg RuPZn 2 (73\% yield based on the EPZn 2 starting material) after purification. ${ }^{1} \mathrm{H}$ NMR (500 MHZ, $\left.\mathrm{CD}_{3} \mathrm{CN}\right): \delta 10.33(\mathrm{~d}, 2 \mathrm{H}, J=4.5 \mathrm{~Hz}), 10.31(\mathrm{~d}, 2 \mathrm{H}, J$ $=4.4 \mathrm{~Hz}), 10.14(\mathrm{~s}, 1 \mathrm{H}), 9.96(\mathrm{~d}, 2 \mathrm{H}, J=4.5 \mathrm{~Hz}), 9.40(\mathrm{~s}, 2 \mathrm{H}), 9.31(\mathrm{~d}, 2 \mathrm{H}, J=4.4 \mathrm{~Hz})$, $9.06(\mathrm{~d}, 2 \mathrm{H}, J=4.5 \mathrm{~Hz}), 8.98(\mathrm{~d}, 2 \mathrm{H}, J=4.5 \mathrm{~Hz}), 8.95(\mathrm{~d}, 2 \mathrm{H}, J=4.4 \mathrm{~Hz}), 8.88(\mathrm{~d}, 2 \mathrm{H}, J$ $=4.3 \mathrm{~Hz}), 8.81(\mathrm{~d}, 2 \mathrm{H}, J=8.1 \mathrm{~Hz}), 8.80(\mathrm{~d}, 2 \mathrm{H}, J=8.3 \mathrm{~Hz}), 8.54(\mathrm{~d}, 2 \mathrm{H}, J=8.2 \mathrm{~Hz})$, $8.47(\mathrm{t}, 1 \mathrm{H}, J=8.34 \mathrm{~Hz}), 8.07(\mathrm{td}, 2 \mathrm{H}, J=7.8 \mathrm{~Hz}, J=1.3 \mathrm{~Hz}), 7.96(\mathrm{td}, 2 \mathrm{H}, J=8.0 \mathrm{~Hz}$, $J=1.4 \mathrm{~Hz}), 7.85(\mathrm{t}, 2 \mathrm{H}, J=8.7 \mathrm{~Hz}), 7.84(\mathrm{t}, 2 \mathrm{H}, J=8.7 \mathrm{~Hz}), 7.58(\mathrm{~d}, 2 \mathrm{H}, J=5.1 \mathrm{~Hz})$, $7.44(\mathrm{~d}, 2 \mathrm{H}, J=5.2 \mathrm{~Hz}), 7.23(\mathrm{~m}, 12 \mathrm{H}), 4.08(\mathrm{t}, 8 \mathrm{H}, J=7.1 \mathrm{~Hz}), 4.04(\mathrm{td}, 8 \mathrm{H}, J=7.3$ 
$\mathrm{Hz}, J=2.2 \mathrm{~Hz}), 0.92(\mathrm{t}, 8 \mathrm{H}, J=7.1 \mathrm{~Hz}), 0.86(\mathrm{t}, 8 \mathrm{H}, J=7.1 \mathrm{~Hz}) 0.27(\mathrm{~s}, 36 \mathrm{H}), 0.24(\mathrm{~s}$, 36H). MALDI-TOF: $m / z=2465.41$ (calculated for $\mathrm{C}_{146} \mathrm{H}_{154} \mathrm{~N}_{14} \mathrm{O}_{8} \mathrm{RuZn}_{2}\left(\mathrm{M}-2 \mathrm{PF}_{6}\right)^{+}$ 2465.41).

\section{Ruthenium(II) [5-(4'-ethynyl-(2,2';6',2"-terpyridinyl))-15-[(5',-,10',,20"',} bis(2,6-bis(3,3-dimethyl-1-butyloxy)phenyl)porphinato)zinc(II)]-10,20-bis(2,6bis(3,3-dimethyl-1-butyloxy)phenyl)porphinato)zinc(II)][4'-pyrrolidin-1-yl2,2';6',2"-terpyridine] bis(hexafluorophosphate) (Pyr $\left.{ }_{1} \mathbf{R u P Z n}_{2}\right)$. Reaction of EPZn (20.0 mg, $0.011 \mathrm{mmol}), \mathbf{P y r}_{1} \mathbf{R u B r}(13 \mathrm{mg}, 0.013 \mathrm{mmol}), \mathrm{Pd}_{2}(\mathrm{dba})_{3}(1.5 \mathrm{mg}, 0.00158$ mmol), and $\mathrm{AsPh}_{3}(6.4 \mathrm{mg}, 0.021 \mathrm{mmol})$ in $7 \mathrm{~mL}$ 6:3:1 MeCN:THF:triethylamine under the conditions outlined in the above procedure gave $21 \mathrm{mg} \mathbf{P y r}_{1} \mathbf{R u P Z n} \mathbf{n}_{\mathbf{2}}$ (71\% yield based on the $\mathbf{E P Z n}$ starting material) after purification. ${ }^{1} \mathrm{H} \mathrm{NMR}\left(500 \mathrm{MHZ}, \mathrm{CD}_{3} \mathrm{CN}\right)$ : $\delta 10.34(\mathrm{~d}, 2 \mathrm{H}, J=4.3 \mathrm{~Hz}), 10.31(\mathrm{~d}, 2 \mathrm{H}, J=4.7 \mathrm{~Hz}), 10.13(\mathrm{~s}, 1 \mathrm{H}), 9.95(\mathrm{~d}, 2 \mathrm{H}, J=4.5$ Hz), 9.35 (s, 2H), $9.31(\mathrm{~d}, 2 \mathrm{H}, J=4.4 \mathrm{~Hz}), 9.05$ (d, 2H, $J=4.5 \mathrm{~Hz}), 8.98(\mathrm{~d}, 2 \mathrm{H}, J=4.5$ $\mathrm{Hz}), 8.95(\mathrm{~d}, 2 \mathrm{H}, J=4.3 \mathrm{~Hz}), 8.88(\mathrm{~d}, 2 \mathrm{H}, J=4.3 \mathrm{~Hz}), 8.79(\mathrm{~d}, 2 \mathrm{H}, J=8.0 \mathrm{~Hz}), 8.50(\mathrm{~d}$, $2 \mathrm{H}, J=8.1 \mathrm{~Hz}), 8.03(\mathrm{td}, 2 \mathrm{H}, J=7.9 \mathrm{~Hz}, J=1.4 \mathrm{~Hz}), 7.87(\mathrm{~m}, 8 \mathrm{H}), 7.60(\mathrm{~d}, 2 \mathrm{H}, J=5.5$ $\mathrm{Hz}), 7.44(\mathrm{~d}, 2 \mathrm{H}, J=5.8 \mathrm{~Hz}), 7.31(\mathrm{td}, 2 \mathrm{H}, J=7.3 \mathrm{~Hz}, J=1.3 \mathrm{~Hz}), 7.23(\mathrm{~d}, 4 \mathrm{H}, J=8.6$ $\mathrm{Hz}), 7.21(\mathrm{~d}, 4 \mathrm{H}, J=8.7 \mathrm{~Hz}), 7.18(\mathrm{t}, 2 \mathrm{H}, J=7.8 \mathrm{~Hz}), 4.06(\mathrm{t}, 8 \mathrm{H}, J=7.0 \mathrm{~Hz}), 4.04(\mathrm{td}$, $8 \mathrm{H}, J=7.4 \mathrm{~Hz}, J=2.3 \mathrm{~Hz}), 3.81(\mathrm{~m}, 4 \mathrm{H}), 2.25(\mathrm{~m}, 4 \mathrm{H}), 0.91(\mathrm{t}, 8 \mathrm{H}, J=7.0 \mathrm{~Hz}), 0.85$ (t, $8 \mathrm{H}, J=7.1 \mathrm{~Hz})(\mathrm{m}, 4 \mathrm{H}), 0.26(\mathrm{~s}, 36 \mathrm{H}), 0.23(\mathrm{~s}, 36 \mathrm{H})$. MALDI-TOF: $m / z=2722.70$ (calculated for $\mathrm{C}_{153} \mathrm{H}_{169} \mathrm{~F}_{6} \mathrm{~N}_{15} \mathrm{O}_{8} \mathrm{PRuZn} \mathrm{n}_{2}\left(\mathrm{M}-\mathrm{PF}_{6}\right)^{+}$2722.89)

Ruthenium(II) [5-(4'-ethynyl-(2,2';6',2'-terpyridinyl))-15-[(5',-,10',,20'"'bis(2,6-bis(3,3-dimethyl-1-butyloxy)phenyl)porphinato)zinc(II)]-10,20-bis(2,6bis(3,3-dimethyl-1-butyloxy)phenyl)porphinato)zinc(II)][4,4',4"'-pyrrolidin-1-yl- 
2,2';6',2"-terpyridine] bis(hexafluorophosphate) $\left(\mathrm{Pyr}_{3} \mathbf{R u P Z n}_{2}\right)$. Reaction of EPZn (16.0 mg, $0.0084 \mathrm{mmol}), \mathbf{P y r}_{3} \mathbf{R u B r}(12 \mathrm{mg}, 0.0105 \mathrm{mmol}), \mathrm{Pd}_{2}(\mathrm{dba})_{3}(1.2 \mathrm{mg}, 0.0013$ mmol), and $\mathrm{AsPh}_{3}(5.2 \mathrm{mg}, 0.017 \mathrm{mmol})$ in $6 \mathrm{~mL}$ 6:3:1 MeCN:THF:triethylamine under the conditions outlined above gave $15 \mathrm{mg} \mathbf{P y r}_{3} \mathbf{R u P Z n _ { 2 }}$ (60\% yield based on the $\mathbf{E P Z n _ { 2 }}$ starting material) after purification. ${ }^{1} \mathrm{H}$ NMR $\left(500 \mathrm{MHZ}, \mathrm{CD}_{3} \mathrm{CN}\right): \delta 10.32(\mathrm{~d}, 2 \mathrm{H}, J=$ $4.3 \mathrm{~Hz}), 10.31$ (d, 2H, $J=4.5 \mathrm{~Hz}), 10.13(\mathrm{~s}, 1 \mathrm{H}), 9.97$ (br s, 2H), 9.31 (d, 2H, $J=4.3$ Hz), 9.30 (s, 2H), 9.06 (d, 2H, $J=4.4 \mathrm{~Hz}), 8.99$ (d, 2H, $J=4.5 \mathrm{~Hz}), 8.97$ (d, 2H, $J=4.5$ $\mathrm{Hz}), 8.88(\mathrm{~d}, 2 \mathrm{H}, J=4.4 \mathrm{~Hz}), 8.72(\mathrm{~d}, 2 \mathrm{H}, J=8.2 \mathrm{~Hz}), 7.86(\mathrm{~m}, 6 \mathrm{H}), 7.76(\mathrm{~s}, 2 \mathrm{H}), 7.59$ $(\mathrm{d}, 2 \mathrm{H}, J=5.6 \mathrm{~Hz}), 7.42(\mathrm{~d}, 2 \mathrm{H}, J=2.3 \mathrm{~Hz}), 7.27(\mathrm{t}, 2 \mathrm{H}, J=7.2 \mathrm{~Hz}), 7.25(\mathrm{~d}, 4 \mathrm{H}, J=$ $8.7 \mathrm{~Hz}), 7.20(\mathrm{~d}, 4 \mathrm{H}, J=8.6 \mathrm{~Hz}), 6.61(\mathrm{~d}, 2 \mathrm{H}, J=6.8 \mathrm{~Hz}), 5.93($ br s, $2 \mathrm{H}), 4.07$ (t, $8 \mathrm{H}, J$ $=7.0 \mathrm{~Hz}), 4.01(\mathrm{t}, 8 \mathrm{H}, J=6.3 \mathrm{~Hz}), 3.81(\mathrm{~m}, 4 \mathrm{H}), 3.45(\mathrm{br} \mathrm{s}, 8 \mathrm{H}), 2.26(\mathrm{~m}, 4 \mathrm{H}), 1.95(\mathrm{~m}$, $8 \mathrm{H}), 0.90(\mathrm{~m}, 8 \mathrm{H}), 0.83(\mathrm{t}, 8 \mathrm{H}, J=7.2 \mathrm{~Hz}) 0.30(\mathrm{~s}, 36 \mathrm{H}), 0.27(\mathrm{~s}, 36 \mathrm{H})$. MALDI-TOF: $m / z=2860.88$ (calculated for $\left.\mathrm{C}_{161} \mathrm{H}_{183} \mathrm{~F}_{6} \mathrm{~N}_{17} \mathrm{O}_{8} \mathrm{PRuZn}_{2}\left(\mathrm{M}-\mathrm{PF}_{6}\right)^{+} 2861.10\right)$.

Osmium (II) [5-(4'-ethynyl-(2,2';6',2"-terpyridinyl))-15-[(5',-,10',,20'”bis(2,6-bis(3,3-dimethyl-1-butyloxy)phenyl)porphinato)zinc(II)]-10,20-bis(2,6bis(3,3-dimethyl-1-butyloxy)phenyl)porphinato)zinc(II)][2,2';6',2'"-terpyridine] bis(hexafluorophosphate) (OsPZn $)$. Reaction of EPZn 2 (50.0 mg, $0.026 \mathrm{mmol}), \mathbf{O s B r}$ (35 mg, $0.034 \mathrm{mmol}), \mathrm{Pd}_{2}(\mathrm{dba})_{3}(4.8 \mathrm{mg}, 0.0053 \mathrm{mmol})$, and $\mathrm{AsPh}_{3}(16.1 \mathrm{mg}, 0.0527$ mmol) in $50 \mathrm{~mL}$ 6:3:1 MeCN:THF:triethylamine under the conditions outlined above gave $40 \mathrm{mg} \mathbf{O s P Z n _ { 2 }}$ (53\% yield based on the $\mathbf{E P Z n} \mathbf{n}_{2}$ starting material) after purification. ${ }^{1} \mathrm{H}$ NMR (500 MHZ, $\left.\mathrm{CD}_{3} \mathrm{CN}\right): \delta 10.33(\mathrm{~d}, 2 \mathrm{H}, J=4.4 \mathrm{~Hz}), 10.30$ (d, 2H, $\left.J=4.4 \mathrm{~Hz}\right)$, $10.13(\mathrm{~s}, 1 \mathrm{H}), 9.97(\mathrm{~d}, 2 \mathrm{H}, J=4.4 \mathrm{~Hz}), 9.41(\mathrm{~s}, 2 \mathrm{H}), 9.31$ (d, 2H, $J=4.3 \mathrm{~Hz}), 9.06$ (d, $2 \mathrm{H}, J=4.4 \mathrm{~Hz}), 8.98(\mathrm{~d}, 2 \mathrm{H}, J=4.4 \mathrm{~Hz}), 8.96(\mathrm{~d}, 2 \mathrm{H}, J=4.4 \mathrm{~Hz}), 8.88(\mathrm{~d}, 2 \mathrm{H}, J=4.3$ 
$\mathrm{Hz}), 8.81(\mathrm{~d}, 2 \mathrm{H}, J=8.3 \mathrm{~Hz}), 8.78(\mathrm{~d}, 2 \mathrm{H}, J=8.0 \mathrm{~Hz}), 8.51(\mathrm{~d}, 2 \mathrm{H}, J=8.3 \mathrm{~Hz}), 7.99(\mathrm{t}$, $1 \mathrm{H}, J=8.3 \mathrm{~Hz}), 7.91(\mathrm{td}, 2 \mathrm{H}, J=7.9 \mathrm{~Hz}, J=1.1 \mathrm{~Hz}), 7.86(\mathrm{t}, 2 \mathrm{H}, J=8.7 \mathrm{~Hz}), 7.83(\mathrm{t}$, $2 \mathrm{H}, J=8.7 \mathrm{~Hz}), 7.80(\mathrm{t}, 2 \mathrm{H}, J=8.7 \mathrm{~Hz}), 7.58(\mathrm{td}, 2 \mathrm{H}, J=7.5 \mathrm{~Hz}, J=1.2 \mathrm{~Hz}), 7.43(\mathrm{~d}$, $2 \mathrm{H}, J=5.6 \mathrm{~Hz}), 7.32(\mathrm{~d}, 2 \mathrm{H}, J=5.0 \mathrm{~Hz}), 7.23(\mathrm{~d}, 4 \mathrm{H}, J=8.7 \mathrm{~Hz}), 7.21(\mathrm{~d}, 4 \mathrm{H}, J=8.8$ $\mathrm{Hz}), 7.18(\mathrm{td}, 2 \mathrm{H}, J=7.2 \mathrm{~Hz}, J=1.2 \mathrm{~Hz}), 7.14(\mathrm{t}, 2 \mathrm{H}, J=7.2 \mathrm{~Hz}), 4.07(\mathrm{t}, 8 \mathrm{H}, J=7.1$ $\mathrm{Hz}), 4.03(\mathrm{td}, 8 \mathrm{H}, J=7.6 \mathrm{~Hz}, J=2.0 \mathrm{~Hz}), 0.91(\mathrm{t}, 8 \mathrm{H}, J=7.1 \mathrm{~Hz}), 0.84(\mathrm{t}, 8 \mathrm{H}, J=7.1$ Hz) $0.29(\mathrm{~s}, 36 \mathrm{H}), 0.25(\mathrm{~s}, 36 \mathrm{H})$. MALDI-TOF: $m / z=2553.92$ (calculated for $\mathrm{C}_{146} \mathrm{H}_{154} \mathrm{~N}_{14} \mathrm{O}_{8} \mathrm{OsZn}_{2}\left(\mathrm{M}-2 \mathrm{PF}_{6}\right)^{+}$2553.88).

\section{Discussion of $\operatorname{Ru}(\mathrm{tpy})_{2}$ and $\mathrm{Os}(\mathrm{tpy})_{2}$ fundamental photophysics.}

A thorough discussion of the photophysics of the hybrid $\mathbf{M P Z} \mathbf{n}_{\mathbf{n}}$ and $\mathbf{P m M P Z \mathbf { n } _ { \mathbf { n } }}$ compounds is best preceded by a brief discussion of the monomeric polypyridyl units, as relevant transient absorption experiments clearly show that the (polypyridyl)metal(II) moiety drives the photophysics of this class of compounds. Scheme S6 shows simple energy level diagrams of the two monomeric units, $\left[\mathbf{R u}(\mathbf{t p y})_{2}\right]^{2+}$ and $\left[\mathbf{O s}(\mathbf{t p y})_{2}\right]^{2+}$. The absorption events (blue lines) reflect what is observed in the ground-state electronic absorption spectra of these species (see, for example, the spectra of $\mathbf{M B r}$ precursors displayed in Figure S1). Both compounds feature a fairly intense spin-allowed ${ }^{1}$ MLCT transition. Absorption to this state results in fast (sub-ps) internal conversion to the ${ }^{3}$ MLCT state (dashed blue line); additionally the osmium complex features a weak spin-

forbidden transition to the ${ }^{3} \mathrm{MLCT}$ state directly from the ground state. (The high-energy $\pi-\pi^{*}$ LL transitions are not shown in this diagram.) 
The relaxation dynamics of the ${ }^{3}$ MLCT state to the ground-state surface depends on the nature of the metal center. A discussion of the ${ }^{3}$ MLCT relaxation dynamics of $\left[\mathbf{M}(\mathbf{t p y})_{2}\right]^{2+}$ is best prefaced by pointing out that in these species, the poor bite angle of terpyridine results in a significant distortion of the ligand field from octahedral symmetry; such a distortion lowers of the energy of the metal-centered $\left({ }^{3} \mathrm{MC}\right)$ (ligand field) states compared to the more perfectly octahedral crystal field characterized by the analogous tris(bipyridine)metal(II) complexes. Thus while the ${ }^{3} \mathrm{MLCT}$ of $\left[\mathbf{R u}(\mathbf{b p y})_{\mathbf{3}}\right]^{\mathbf{2 +}}$ persists for over $1 \mu \mathrm{s}$ and supports luminescence of moderate intensity $(\phi \sim 12 \%),{ }^{13}$ the ${ }^{3} \mathrm{MLCT}$ state of $\left[\mathbf{R u}(\mathbf{t p y})_{2}\right]^{2+}$ is quenched at ambient temperatures by the now low-lying ruthenium(II) ${ }^{3} \mathrm{MC}$ states, and the overall lifetime of the ${ }^{3} \mathrm{MLCT}(\tau \sim 250 \mathrm{ps})^{14}$ is too short to support observable room-temperature luminescence. However, at low (liquid nitrogen) temperatures, the ${ }^{3} \mathrm{MLCT}$ state of $\left[\mathbf{R u}(\mathbf{t p y})_{2}\right]^{2+}$ becomes quite long-lived and undergoes intense ${ }^{3} \mathrm{MLCT}$ luminescence because the ${ }^{3} \mathrm{MC}$ quenching states are no longer thermally accessible.

In contrast to the photophysics of $\left[\mathbf{R u}(\mathbf{t p y})_{2}\right]^{\mathbf{2}^{+}}$, thermal population of the ${ }^{3} \mathrm{MC}$ states in $\left[\mathbf{O s}(\mathbf{t p y})_{2}\right]^{2+}$ is suppressed, even at room temperature, due to both osmium's lower oxidation potential and its stronger ligand field, with the end result that the ${ }^{3} \mathrm{MLCT} /{ }^{3} \mathrm{MC}$ energy gap is significantly larger in this compound. It should be noted that in comparing $\left[\mathbf{O s}(\mathbf{b p y})_{3}\right]^{2+}$ and $\left[\mathbf{R u}(\mathbf{b p y})_{3}\right]^{2+}$, the latter compound has the longer lived ${ }^{3}$ MLCT state and hence larger quantum yield of luminescence, because of osmium's larger spin-orbit coupling constant, which facilitates more efficient intersystem crossing to the (singlet) ground-state surface. Conversely, in the bis(terpyridine) compexes, the two metals display a reverse trend at room temperature, with $\left[\mathbf{O s}(\mathbf{t p y})_{2}\right]^{2+}$ featuring the 
longer ${ }^{3}$ MLCT state lifetime $(\sim 269 \mathrm{~ns})^{14}$ and observable luminescence. Yet, at $77 \mathrm{~K}$, where the ${ }^{3} \mathrm{MC}$ states are inaccessible for both species, the ruthenium complex is the longer lived of the two due to the spin-orbit coupling of osmium, as discussed above.

Although it is true that $\left[\mathbf{R u}(\mathbf{t p y})_{2}\right]^{2+,}$ s short excited-state lifetime is a photophysical disadvantage, for geometrical reasons, $\left[\mathbf{R u}(\mathbf{t p y})_{2}\right]^{2+}$ is actually favored over $\left[\mathbf{R u}(\mathbf{b p y})_{3}\right]^{2+}$ for the construction of large, supermolecular architectures. Thus, much work been done to increase the luminescence quantum yield and lengthen the ${ }^{3}$ MLCT lifetime of $\left[\mathbf{R u}(\mathbf{t p y})_{2}\right]^{2+}$ complexes An obvious strategy is to increase the ${ }^{3} \mathrm{MLCT} /{ }^{3} \mathrm{MC}$ energy gap by either (a) increasing the conjugation of the terpyridine ligand ${ }^{15}$ or (b) adding electron donating or withdrawing substituents on the terpyridyl ligand. ${ }^{16}$ For instance, substituting terpyridine in the 4' position with a methyl-sulfoxide group has been shown to increase the excited-state lifetime of $\left[\mathbf{R u}(\mathbf{t p y})_{2}\right]^{2+}$ by a factor of 100 and leads to weak emission at $298 \mathrm{~K} .{ }^{16}$ The ability to dramatically increase the excited-state lifetime of $\left[\mathbf{R u}(\mathbf{t p y})_{2}\right]^{2+}$ by simple modifications to the terpyridyl ligand has important implications on the photophysics of MPZn, as demonstrated in this work. For additional information on these topics, the reader is pointed towards the numerous quality reviews that have been written on metal(polypyridyl) photophysics. ${ }^{14,17-19}$

\section{Low Temperature Emission of OsPZn ${ }_{2}$.}

As discussed in the text, the fluorescence of $\mathbf{O S P Z \mathbf { n } _ { 2 }}$ is quenched by over an order of magnitude with respect to that of $\mathbf{R u P Z n _ { 2 }}$, despite the fact that the fluorescence signature of both of these compounds occurs at the same energy and derives from spontaneous emission from the same ligand-localized excited singlet electronic-state. 
The origin of the strong emission of $\mathbf{R u P Z \mathbf { n } _ { 2 }}$ derives from the fact that in this species, the ligand-localized singlet is sufficiently lower in energy than the long-lived 3MLCT state that the latter state cannot be efficiently populated at ambient temperature. On the other hand, as highlighted in the $\mathbf{O s P Z n _ { 2 }}$ EAS (Figure 1), the ${ }^{3}$ MLCT and $\mathrm{S}_{1}$ states of OsPZn2 appear to lie in close energetic proximity to one another. Low temperature (77K) emission spectroscopy (Figure S6) demonstrates an order-of-magnitude increase in the $\mathbf{O s P Z n} \mathbf{n}_{2}$ integrated fluorescence intensity relative to that observed at room temperature, which would indicate that the ${ }^{3}$ MLCT state lies slightly above the $\mathrm{S}_{1}$ state. Thus, at $77 \mathrm{~K}$, electronically excited $\mathbf{O s P Z n _ { 2 }}$ clearly lacks sufficient thermal energy to efficiently populate the ${ }^{3}$ MLCT state and relaxes primarily by the same processes governing $\mathrm{S}_{1}$-state relaxation in $\mathbf{R u P Z n _ { 2 }}$. The presence of a slight thermal activation barrier for $\mathrm{S}_{1}{ }^{3}{ }^{3} \mathrm{MLCT}$ inter-system crossing is also consistent with the observed $\mathbf{O s P Z \mathbf { n } _ { 2 }}$ * and OsPZn* charge-separation dynamics, underscoring that this energy gap is a primary determinant of the fate of the initially prepared excited state in these $\mathbf{M P Z \mathbf { n } _ { \mathbf { n } }}$ chromophores. Nevertheless, it is worth pointing out that the (relaxed) ${ }^{3}$ MLCT energy may be sensitive to temperature, as at very low temperatures, solvent relaxation of the highly polarized MLCT state would be inhibited. Thus while at low temperatures the fluorescent singlet state is lower in energy than the ${ }^{3}$ MLCT state, it is possible that the $\mathrm{S}_{1}$ ${ }^{3}$ MLCT energy gap (and even the energetic ordering of the two states) is different at the two measured temperatures. Though, given the relatively slow timescale for charge separation in $\mathbf{O s P Z n} 2(\sim 13 \mathrm{ps})$ relative to that observed in $\mathbf{O s P Z n}(<200 \mathrm{fs})$, a thermal activation barrier for charge separation at room temperature is a reasonable conclusion. 


\section{Supplemental Schemes and Figures.}

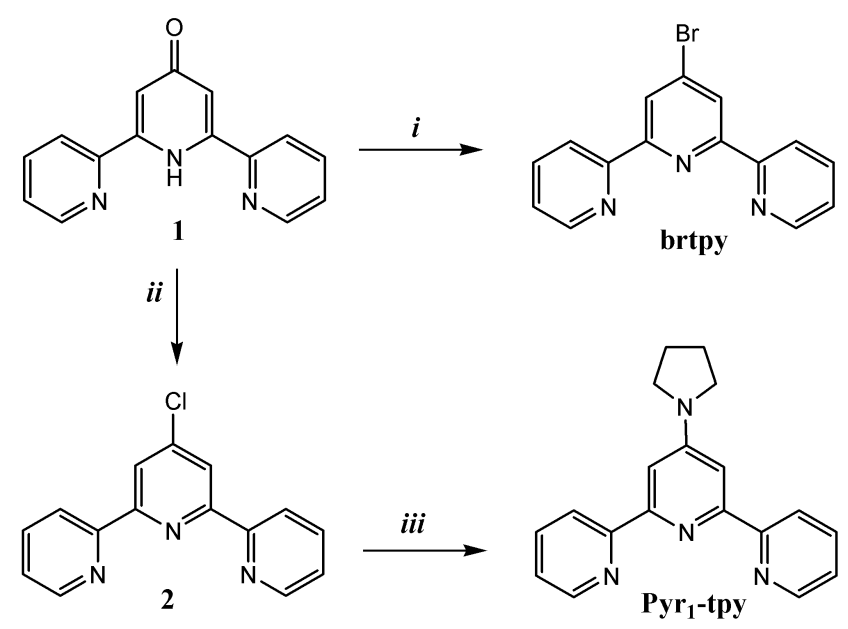

Scheme S1. The synthesis of terpyridine ligands 4'-bromo-2, 2';6',2'-terpyridine (brtpy) and 4'-pyrrolidin-1-yl-2,2';6',2"'-terpyridine (Pyr $\mathbf{1}_{\mathbf{1}}$-tpy) from 2,6-bis(2-pyridyl)-4(1H)pyridone (1). ${ }^{1,2}$ (i) $\mathrm{POBr}_{3}, \mathrm{PBr}_{5}, 100{ }^{\circ} \mathrm{C}, 16$ h.; (ii) $\mathrm{POCl}_{3}, \mathrm{PCl}_{5}, 100{ }^{\circ} \mathrm{C}, 16$ h.; (iii) ferrous chloride, pyrrolidine, 2-propanol, reflux $18 \mathrm{~h}$.; then $\mathrm{H}_{2} \mathrm{O}_{2}, \mathrm{NaOH}$.
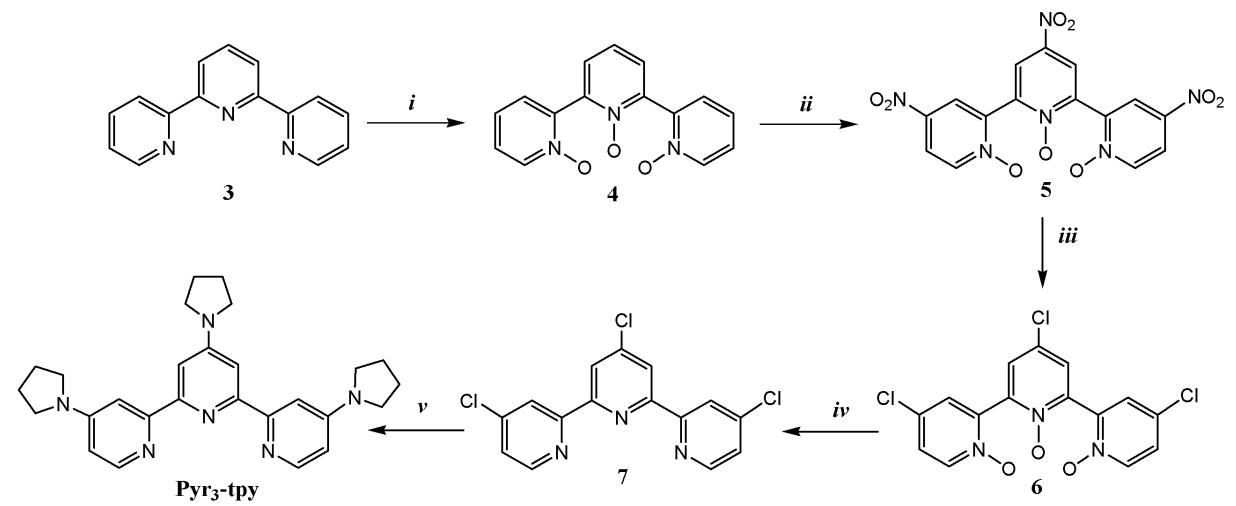

Scheme S2. The synthesis of terpyridine ligand 4,4',4"'-tris(pyrrolidin-1-yl)-2,2';6',2"'terpyridine ( $\mathbf{P y r}_{3}$-tpy) from 2,2';6',2"-terpyridine (3). (i) acetic acid, $\mathrm{H}_{2} \mathrm{O}_{2}, 90{ }^{\circ} \mathrm{C}, 16 \mathrm{~h}$; (ii) fuming $\mathrm{HNO}_{3}$, fuming $\mathrm{H}_{2} \mathrm{SO}_{4}, \mathrm{H}_{2} \mathrm{SO}_{4}, 120^{\circ} \mathrm{C}$, $4 \mathrm{~h}$.; (iii) acetyl chloride, acetic acid, $60{ }^{\circ} \mathrm{C}, 2$ h.; (iv) $\mathrm{PCl}_{3}$, reflux, 1h.; (v)ferrous chloride, pyrrolidine, 2-propanol, reflux 18 h.; then $\mathrm{H}_{2} \mathrm{O}_{2}, \mathrm{NaOH}$. 
Duncan, et. al. Supporting Information J. Am. Chem. Soc.
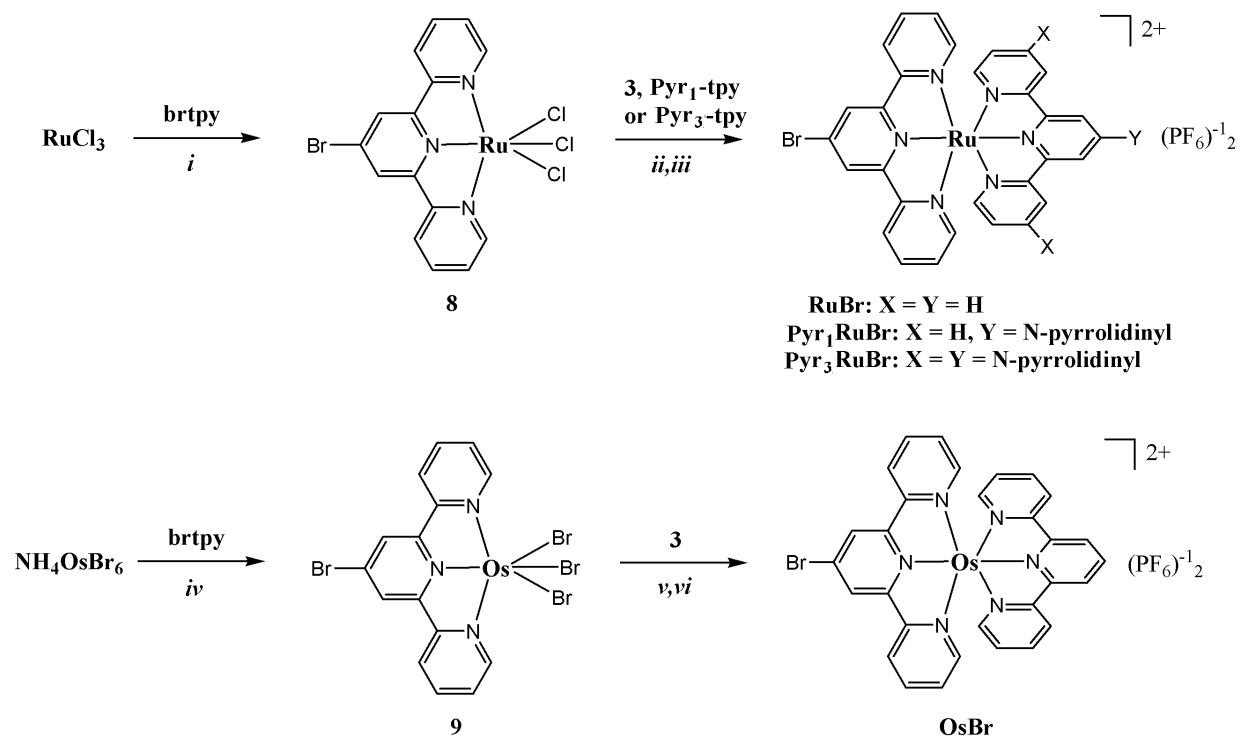

Scheme S3. The synthesis of $\mathbf{R u B r}, \mathbf{P y r}_{1} \mathbf{R u B r}, \mathbf{P y r}_{3} \mathbf{R u B r}$ and $\mathbf{O s B r}$. (i) Methanol, reflux, 20h.; (ii) methanol, N-ethyl-morpholine, reflux, 2h.; (iii) $\mathrm{NH}_{4} \mathrm{PF}_{6}$; (vi) Methanol, reflux, 20h.; (v) ethylene glycol, reflux, 1h.; (vi) $\mathrm{NH}_{4} \mathrm{PF}_{6}$.

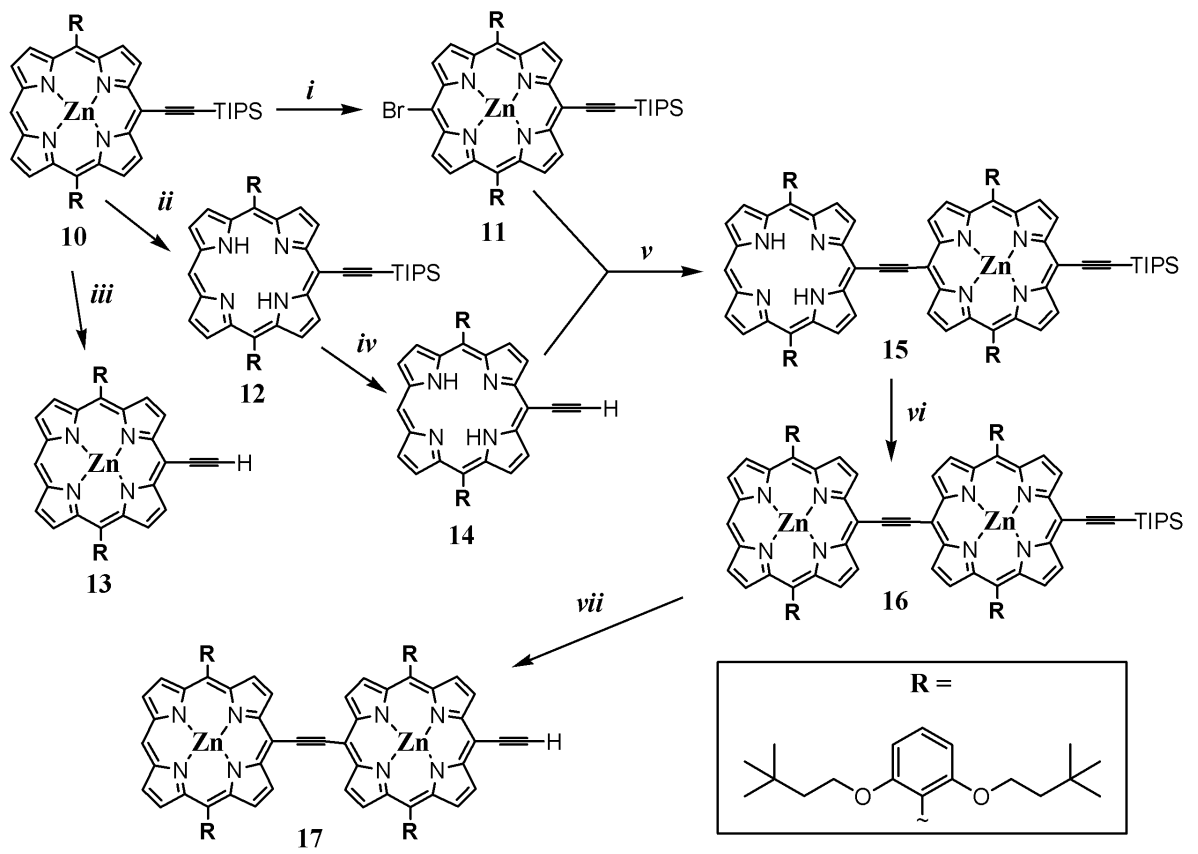

Scheme S4. The synthesis of 13 (EPZn) and $17\left(\mathbf{E P Z n}_{2}\right)$ from 10. (i) n-bromosuccinimide, $\mathrm{CH}_{2} \mathrm{Cl}_{2}$, pyridine, $0{ }^{\circ} \mathrm{C}, 30$ min.; (ii) TFA, $\mathrm{CH}_{2} \mathrm{Cl}_{2}, 25{ }^{\circ} \mathrm{C}, 10$ min.; (iii) TBAF, THF, $25^{\circ} \mathrm{C}, 10$ min.; (iv) TBAF, THF, $25^{\circ} \mathrm{C}, 10$ min.; (v) $\mathrm{Pd}_{2}(\mathrm{dba})_{3}, \mathrm{AsPh}_{3}$, THF, TEA, $60{ }^{\circ} \mathrm{C}$, 16 h.; (vi) $\mathrm{Zn}\left(\mathrm{C}_{2} \mathrm{H}_{3} \mathrm{O}_{2}\right)_{2}, \mathrm{CHCl}_{3}$, reflux, 1.5 h.; (vii) TBAF, THF, 25 ${ }^{\circ} \mathrm{C}, 10 \mathrm{~min}$. 


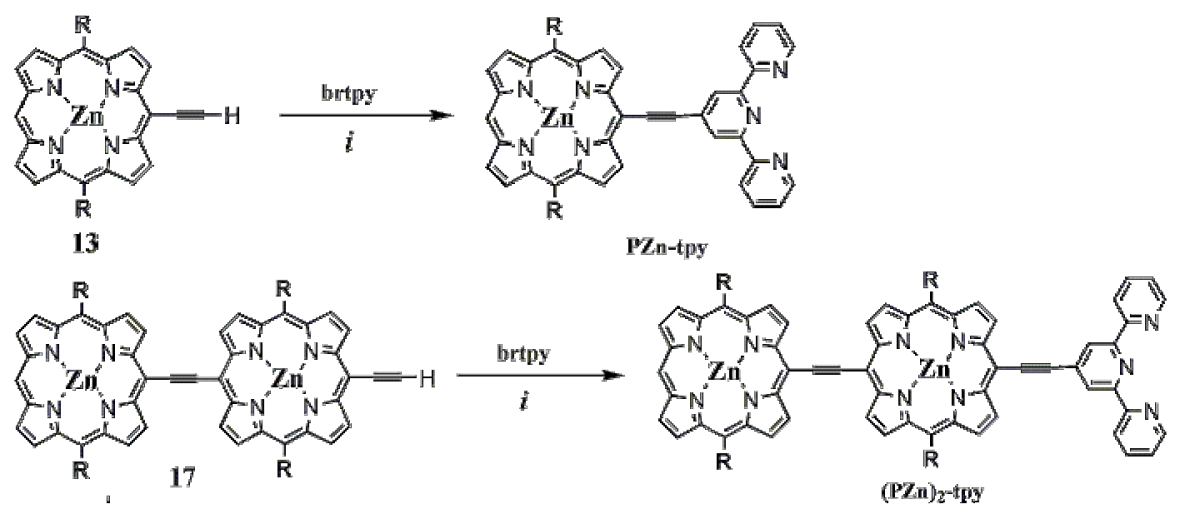

Scheme S5. The synthesis of PZn-tpy and PZn 2 -tpy. (i) $\mathrm{Pd}\left(\mathrm{PPh}_{3}\right)_{4}, \mathrm{CuI}, \mathrm{THF}$, diisopropylamine, $60{ }^{\circ} \mathrm{C}, 16 \mathrm{~h}$. for PZn-tpy; $\mathrm{Pd}_{2}(\mathrm{dba})_{3}, \mathrm{AsPh}_{3}$, THF, TEA, $60{ }^{\circ} \mathrm{C}, 16 \mathrm{~h}$. for $\mathbf{P Z n} \mathbf{n}_{2}$-tpy.
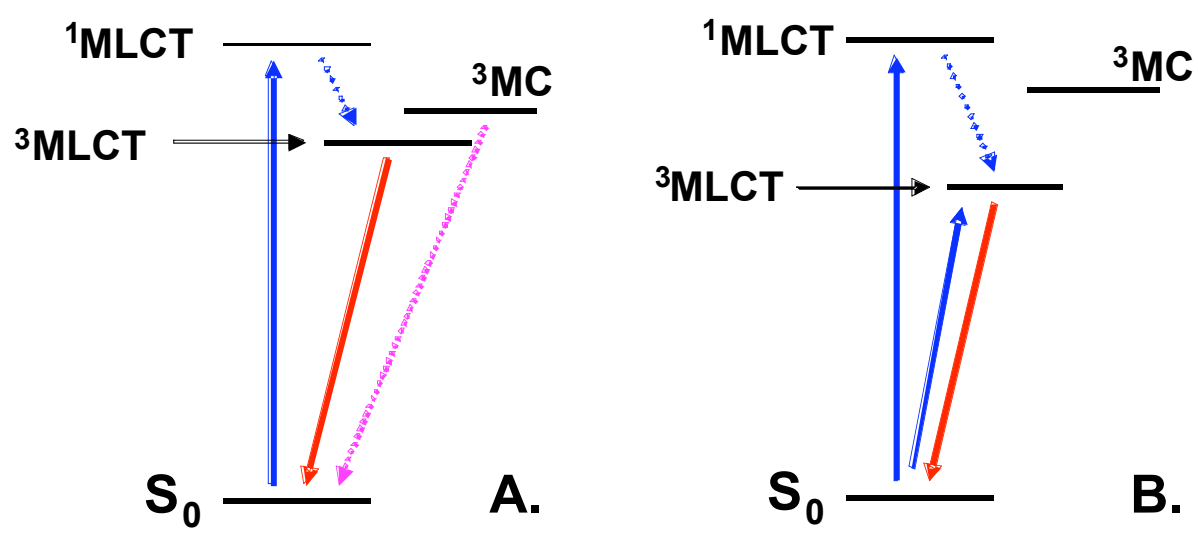

Scheme S6. Energy level diagram and some of the photophysical processes of $\left[\mathbf{M}(\mathbf{t p y})_{2}\right]^{2+}$, where $\mathrm{M}=\mathrm{Ru}(\mathrm{A})$ and $\mathrm{M}=\mathrm{Os}(\mathrm{B})$. Solid blue lines indicate allowed absorptive processes, solid red lines indicate radiative processes, dashed blue lines represent excited-state intersystem crossing and dashed purple lines indicate nonradiative decay via metal-centered (ligand-field) states.

\section{Figure Captions.}

Figure S1. Comparative electronic absorption spectra of (A) RuPZn (blue line) and precursors RuBr (red line) and EPZn (black line), and (B) OsPZn (blue line) and precursors OsBr (red line) and EPZn (black line). The spectra of MPZn and MBr species were recorded in acetonitrile solvent; the spectrum of EPZn was recorded in chloroform solvent. $\mathrm{R}=2$ ',6'-bis(3,3-dimethyl-1-butyloxy)-phenyl.

Figure S2. Electronic absorption spectra of $\mathbf{O s P Z n _ { 2 }}$ (red) and $\mathbf{R u P Z n _ { 2 }}$ (black), normalized to the $\lambda_{\max }\left(\mathrm{S}_{0} \rightarrow \mathrm{S}_{2}\right)$ intensity. The green line represents the difference between the $\mathbf{O S P Z n _ { 2 }}$ and $\mathbf{R u P Z n} \mathbf{n}_{\mathbf{2}}$ spectra. The large peak centered at approximately 750 
$\mathrm{nm}$ represents direct excitation to the quasi-allowed ${ }^{3}$ MLCT state in $\mathbf{O S P Z n _ { 2 }}$ (see text for details). Spectra were recorded in acetonitrile solvent.

Figure S3. Comparative electronic absorption spectra of PZn-tpy and PZn $\mathbf{P}$-tpy in dichloromethane solvent.

Figure S4. Room-temperature fluorescence spectra of PZn-tpy (black line) and PZn $\mathbf{n}_{\mathbf{2}}$ tpy (red line), recorded in dichloromethane solvent. The excitation wavelength was 520 $\mathrm{nm}$. The spectra were normalized for sample absorbance at the excitation wavelength.

Figure S5. Room-temperature fluorescence spectra of $\mathbf{R u P Z \mathbf { n } _ { 2 }}$ in toluene (blue) and butyronitrile (red) solvent. The excitation wavelength was $700 \mathrm{~nm}$. Each spectrum was normalized for the sample absorbance at the excitation wavelength, as well as the solvent index of refraction.

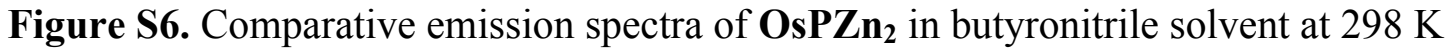
(dark blue) and $77 \mathrm{~K}$ (light blue).

Figure S7 Representative transient absorption spectra at several time delays for: (A) RuPZn and (B) OsPZn. Experimental conditions: solvent $=$ acetonitrile, room temperature, $\lambda_{\text {exc }}=633 \mathrm{~nm}$. A scaled ground-state electronic absorption spectrum, inverted, is displayed for comparison.

Figure S8. Representative $\mathbf{R u P Z n} \mathbf{n}_{2}$ transient absorption spectra at several time delays. Experimental conditions: solvent $=$ acetonitrile, room temperature, $\lambda_{\mathrm{exc}}=(\mathrm{A}) 690 \mathrm{~nm}$ and (B) $\lambda_{\text {exc }}=775 \mathrm{~nm}$. Scaled ground-state electronic absorption and steady-state fluorescence spectra, inverted, are displayed for comparison.

Figure S9. ns- $\mu$ s time-domain transient absorption spectra at selected time delays for: (A) RuPZn, (B) Pyr $\mathbf{P}_{1} \mathbf{R u P Z n}$, (C) Pyr $\mathbf{P}_{3} \mathbf{R u P Z n}$, (D) RuPZn 2 , (E) $\mathbf{P y r}_{1} \mathbf{R u P Z n}_{2}$, (F) $\mathbf{P y r}_{3} \mathbf{R u P Z n}_{2}$, (G) OsPZn, and (H) OsPZn . All spectra were recorded in deoxygenated acetonitrile with an excitation wavelength of $532 \mathrm{~nm}$.

Figure S10. ${ }^{3}$ MLCT excited-state decay dynamics as recorded by ns- $\mu$ s time-domain transient absorption (Figure S11) for: (A) RuPZn, (B) Pyr $\mathbf{R}_{1} \mathbf{R u P Z n}$, (C) Pyr $\mathbf{R} \mathbf{R u P Z n}$, (D) RuPZn 2 , (E) Pyr $\mathbf{R u P Z n}_{2}$, (F) Pyr $\mathbf{R}_{3} \mathbf{R u P Z n}_{2}$, (G) OsPZn, and (H) OsPZn 2 . Dynamics were recorded in anaerobic and aerobic acetonitrile solutions, as indicated, after excitation at $532 \mathrm{~nm}$. Exponential fits of the data are displayed as solid red lines.

Figure S11. Plotted cyclic voltammetric data for (A) RuBr, $\mathbf{P y r}_{1} \mathbf{R u B r}$ and $\mathbf{P y r}_{3} \mathbf{R u B r}$ and (B) OsBr. Experimental conditions: [chromophore] $=\sim 2 \mathrm{mM}$; scan rate $=0.1-0.2$ $\mathrm{V} / \mathrm{s}$; reference electrode: Ag wire. E1/2 values reported are relative to SCE; the ferrocene/ferrocenium couple $(0.43 \mathrm{~V}$ vs SCE) was used as the internal standard. Potentiometric data was obtained in $0.1 \mathrm{M} \mathrm{TBAPF}_{6} /$ acetonitrile electrolyte/solvent system. All reported values correspond to one electron redox couples unless noted otherwise. 
Figure S12. Normalized fluorescence spectra of (A) $\mathbf{R u B r}, \mathbf{P y r}_{1} \mathbf{R u B r}$ and $\mathbf{P y r}_{3} \mathbf{R u B r}$ and (B) $\mathbf{O s B r}$, recorded in acetonitrile solvent at $77 \mathrm{~K}$. The excitation wavelengths were $450 \mathrm{~nm}$ in all cases.

Figure S13. Comparative electronic absorption spectra of $\mathbf{R u B r}, \mathbf{P y r}_{1} \mathbf{R u B r}$ and $\mathbf{P y r}_{3} \mathbf{R u B r}$, recorded in acetonitrile solvent.

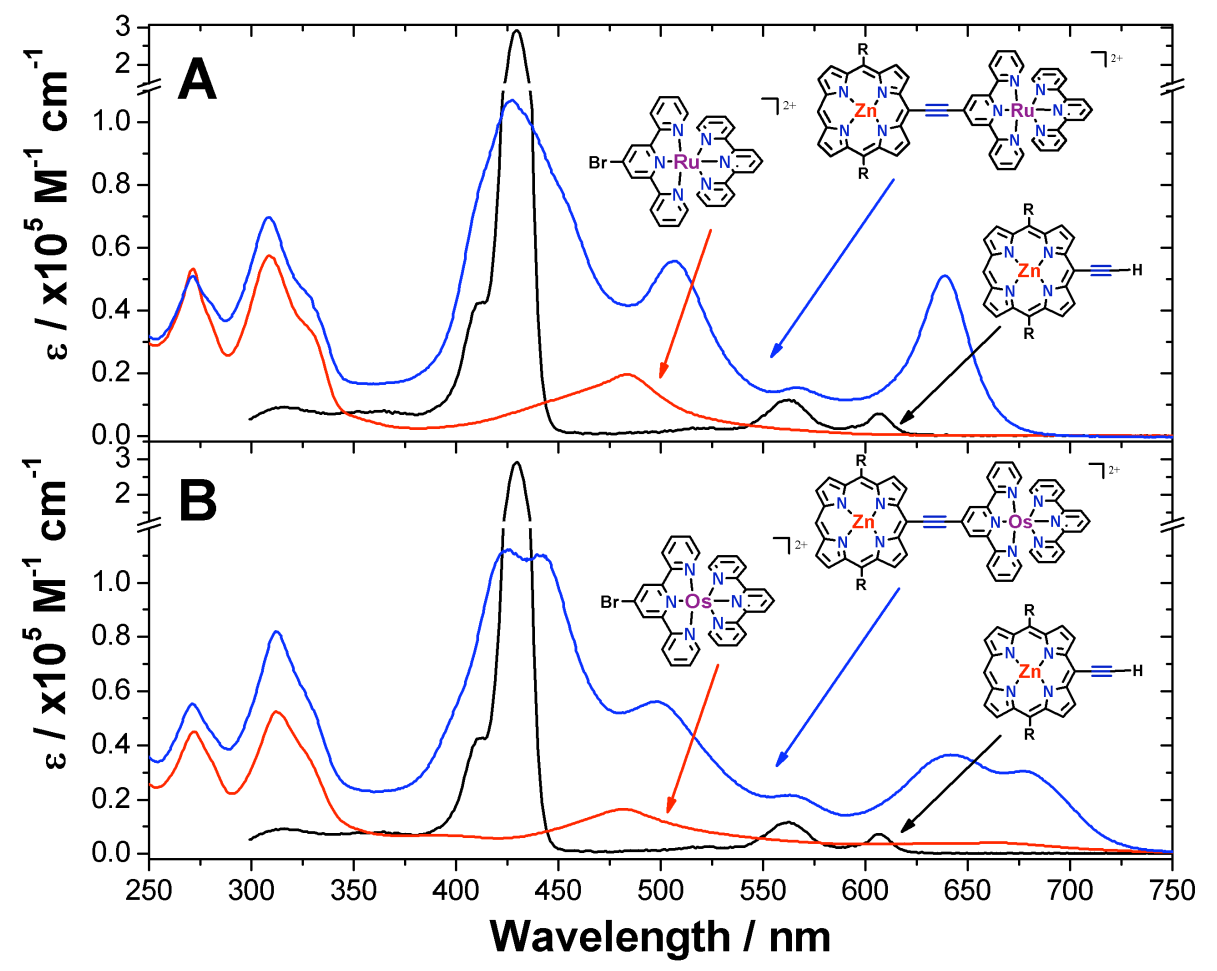

Figure S1. 


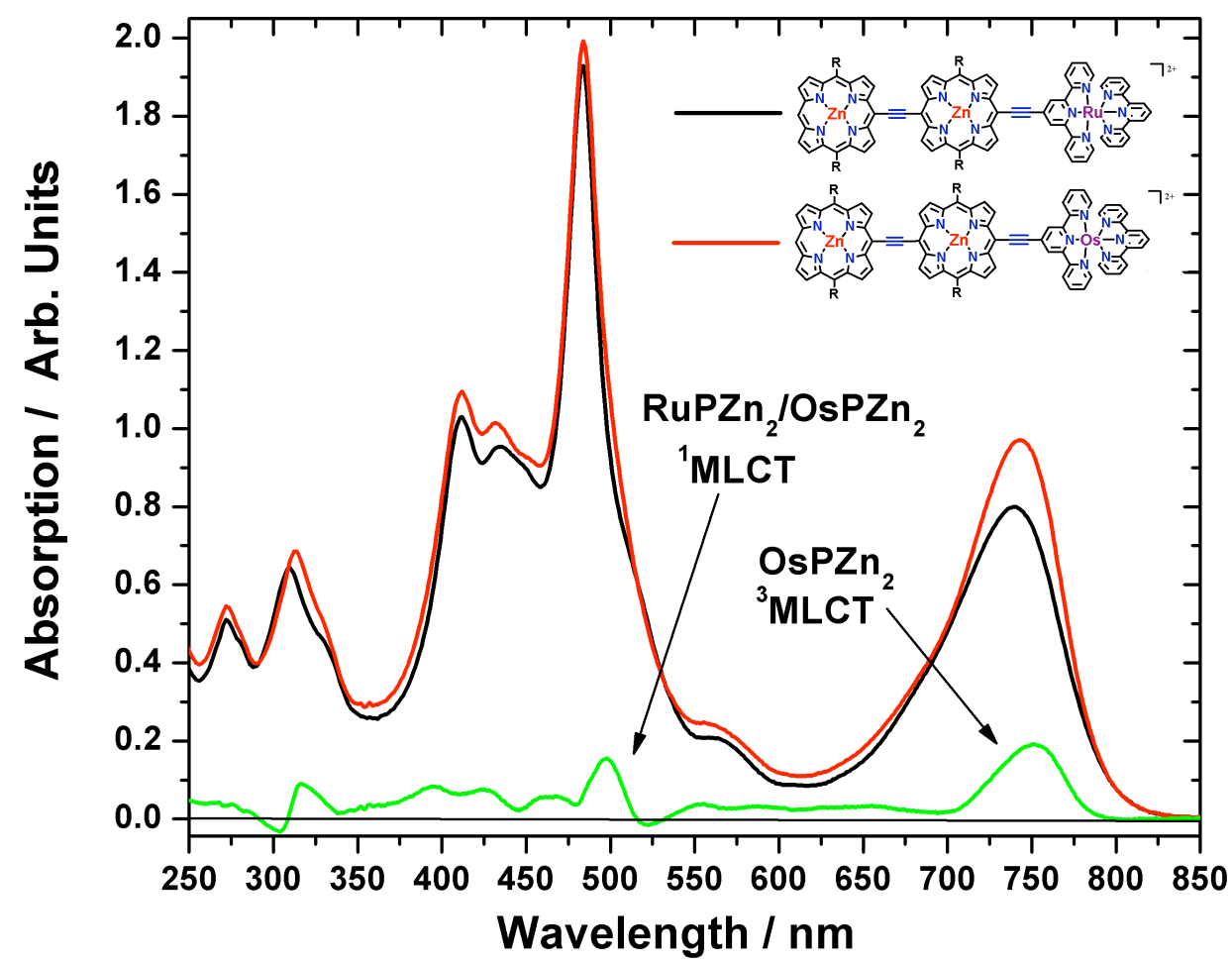

Figure S2

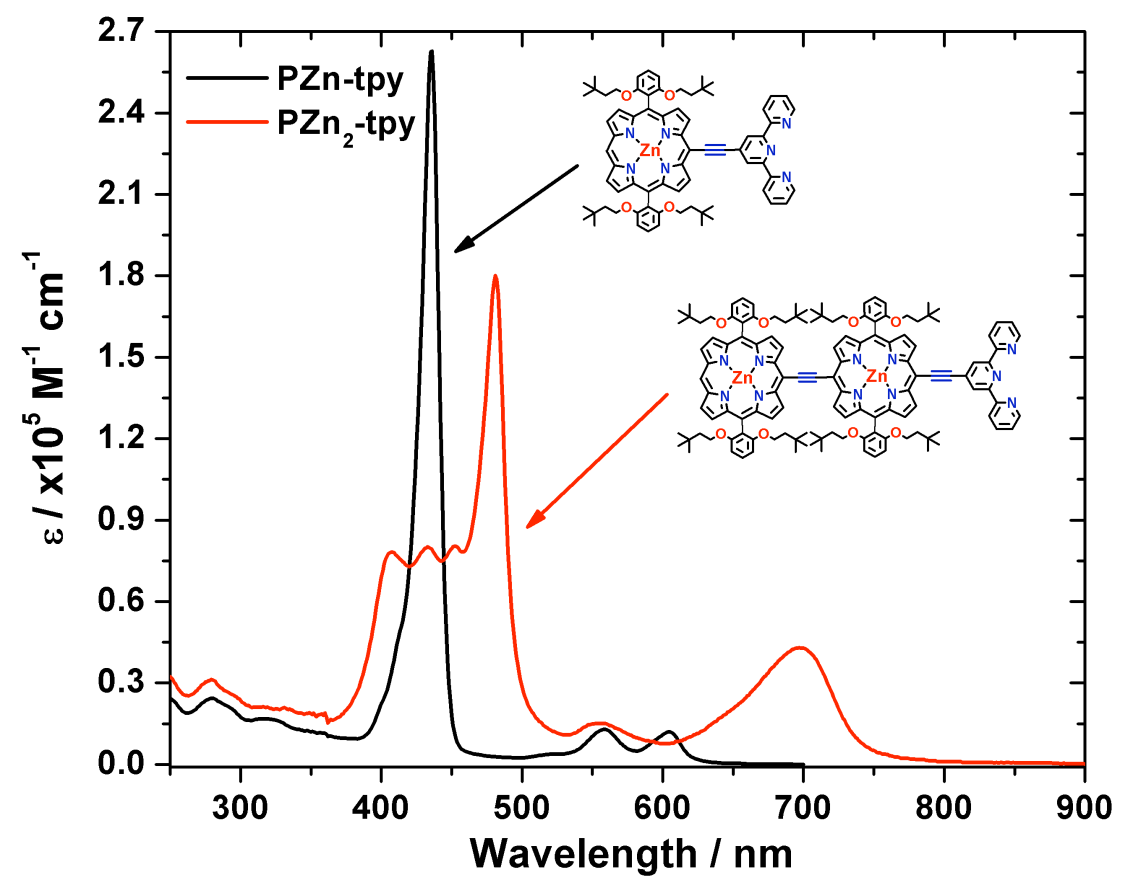

Figure S3. 


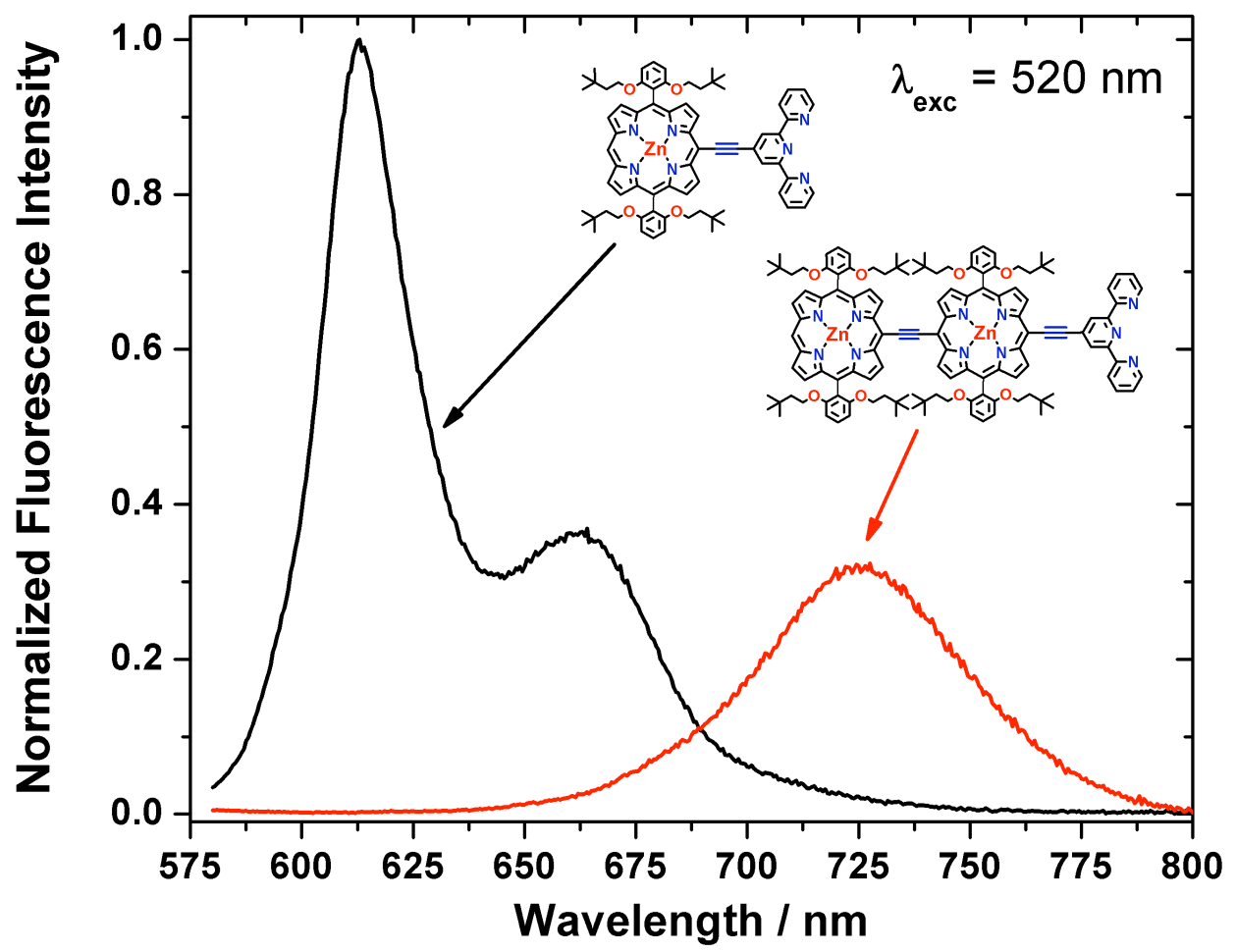

Figure S4.

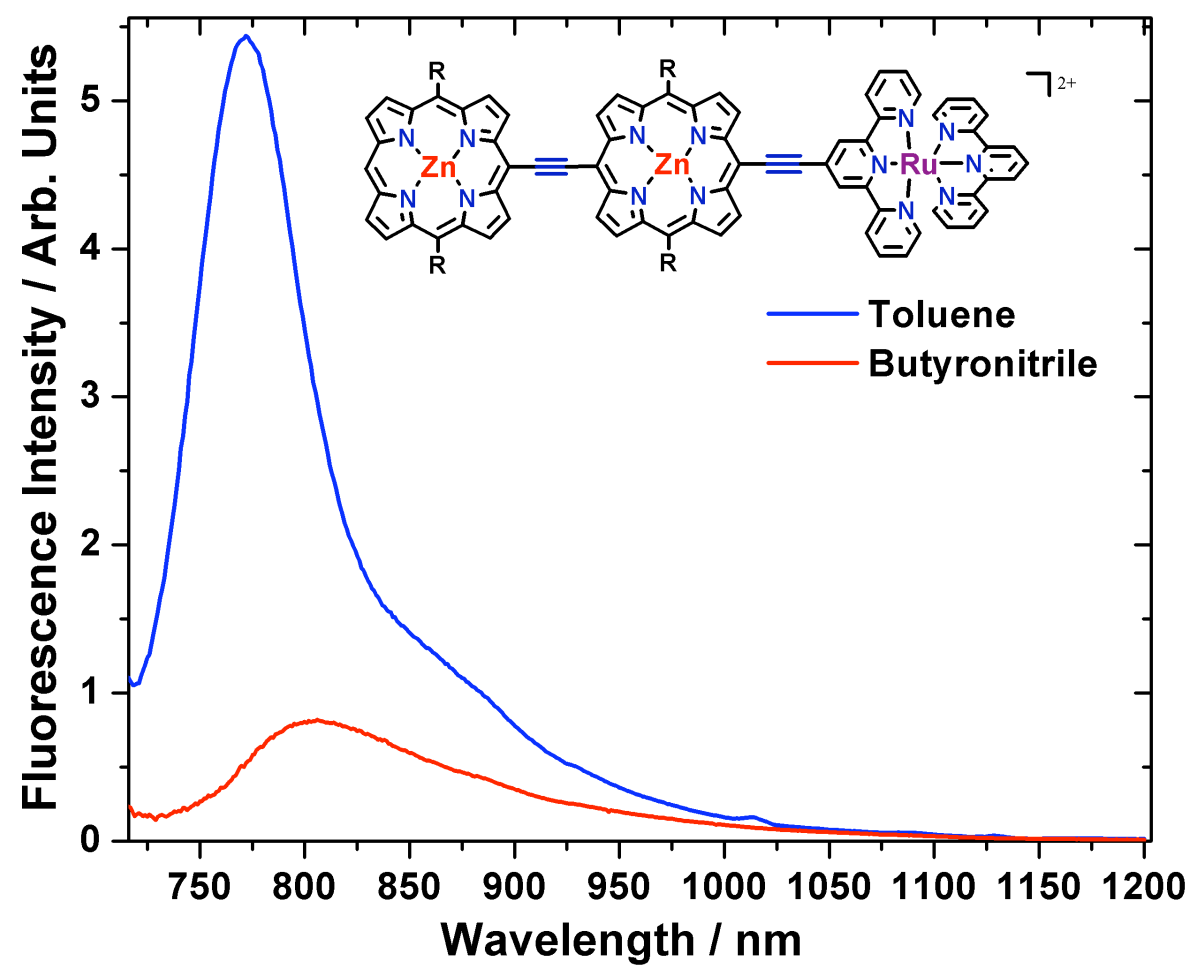

Figure S5. 


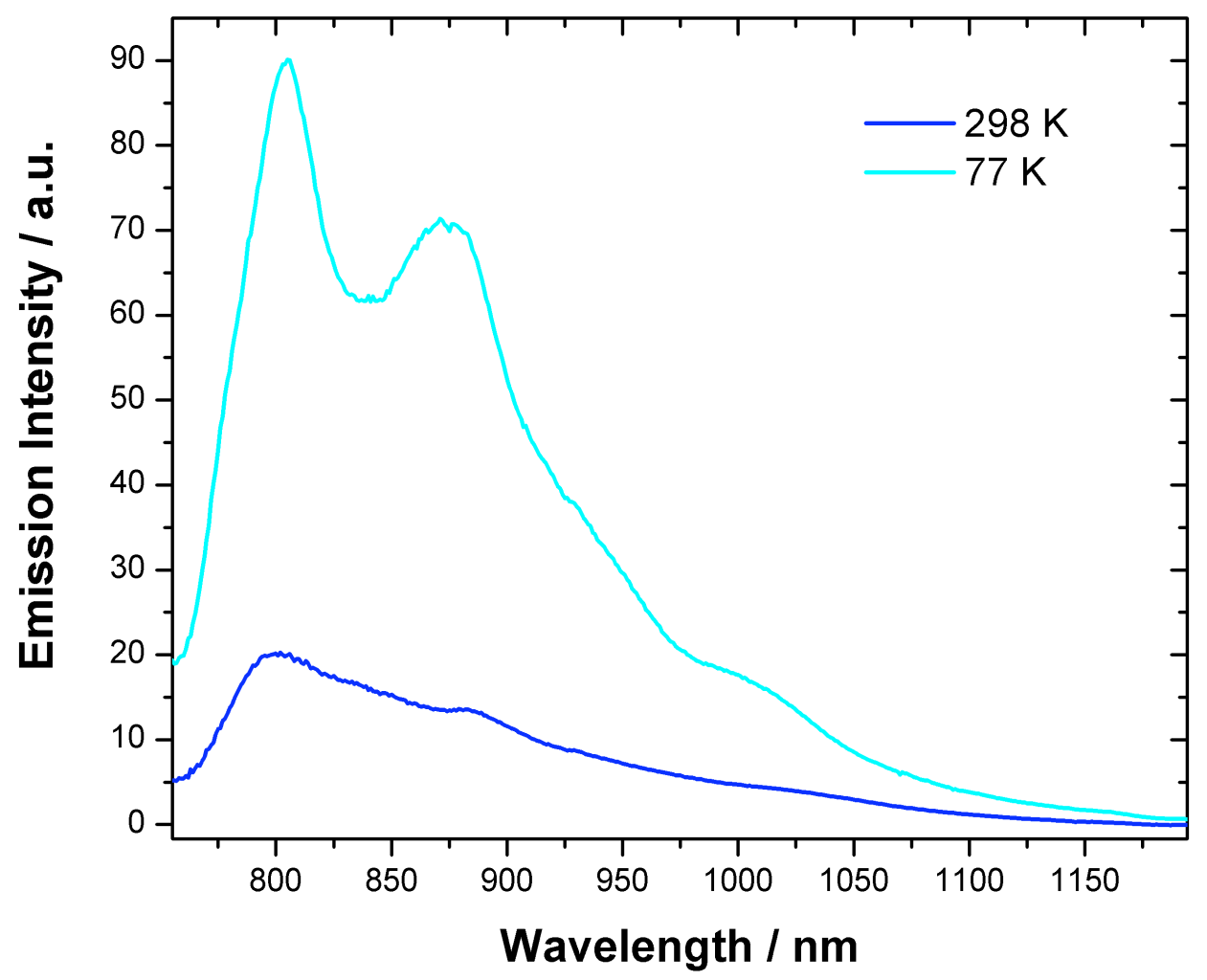

Figure S6

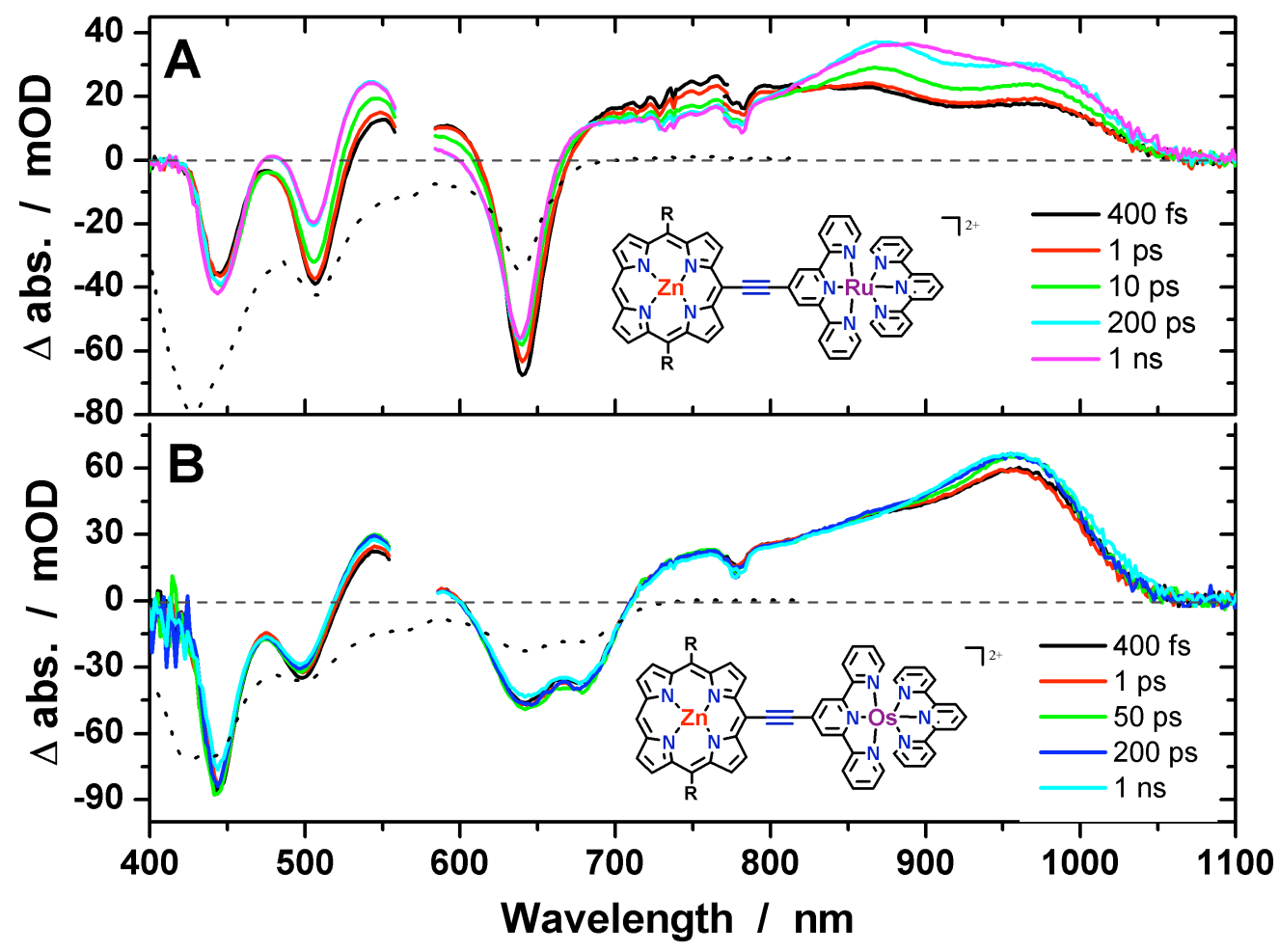

Figure S7. 


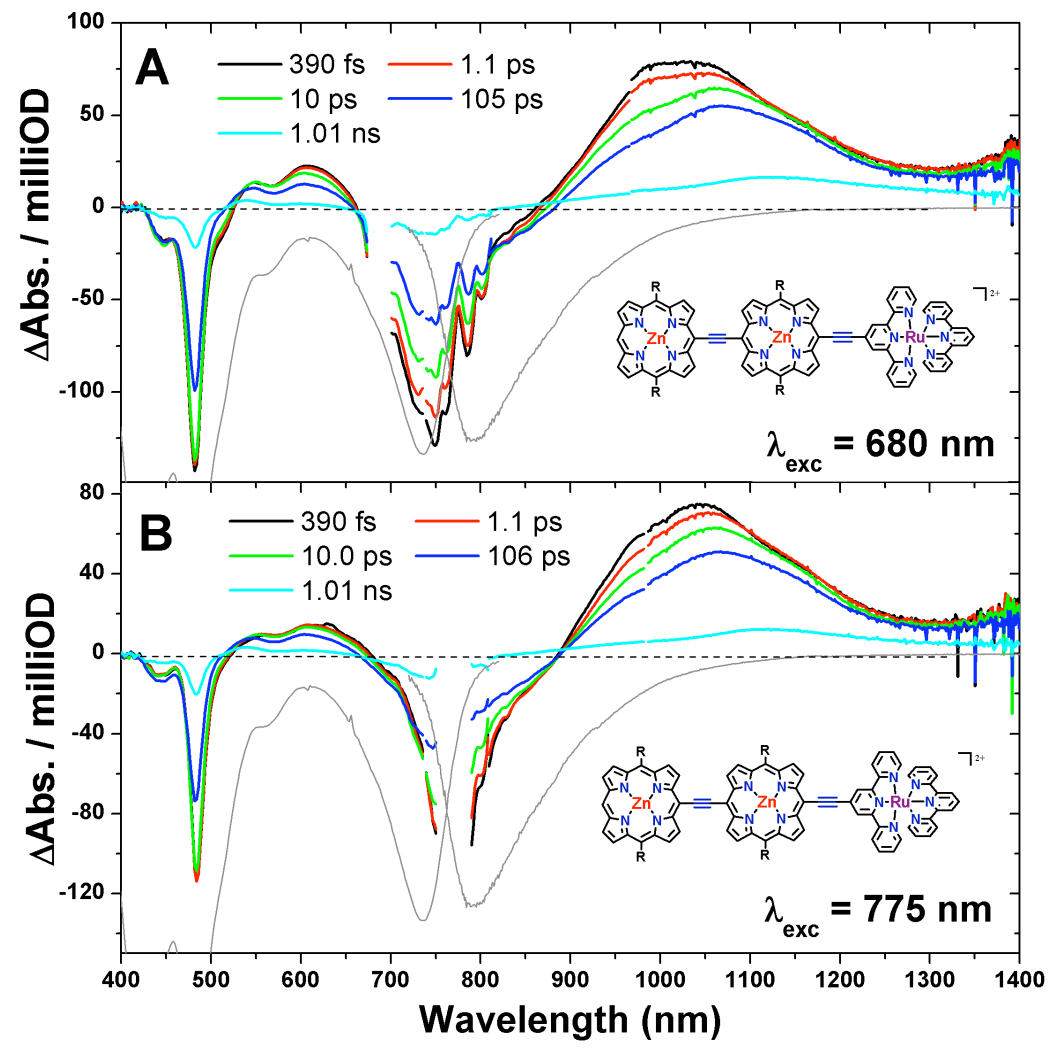

Figure S8
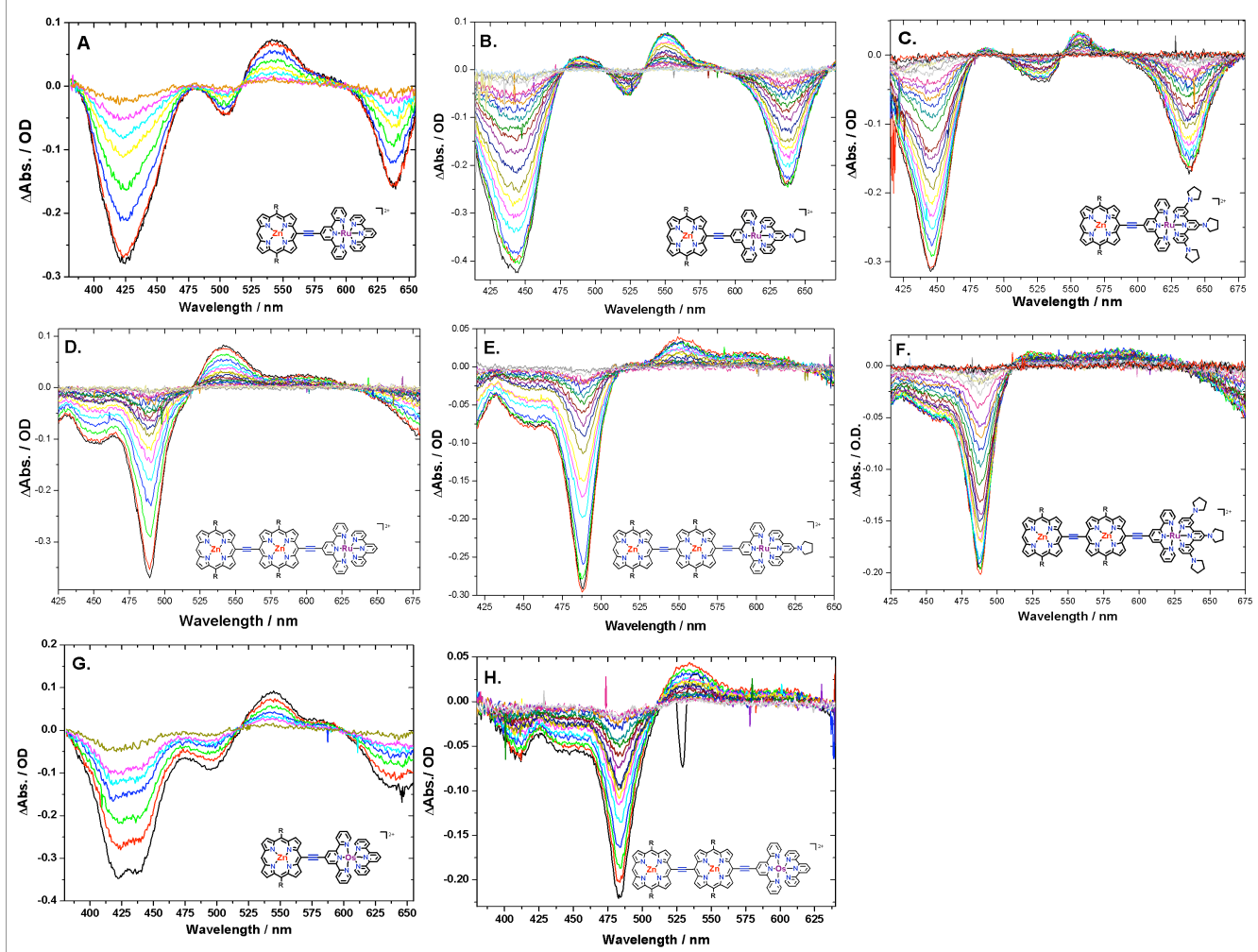

Figure S9. 


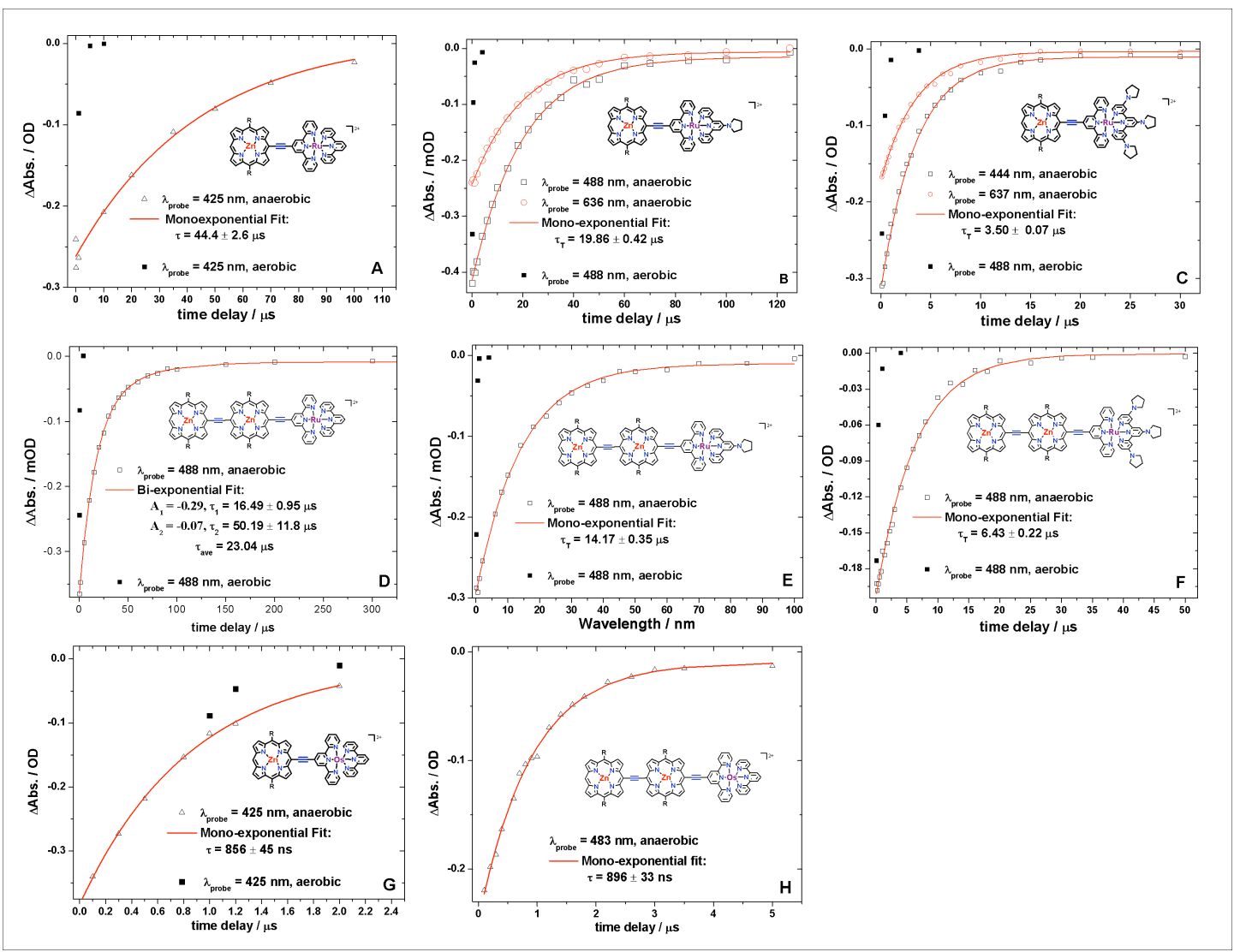

Figure 10.

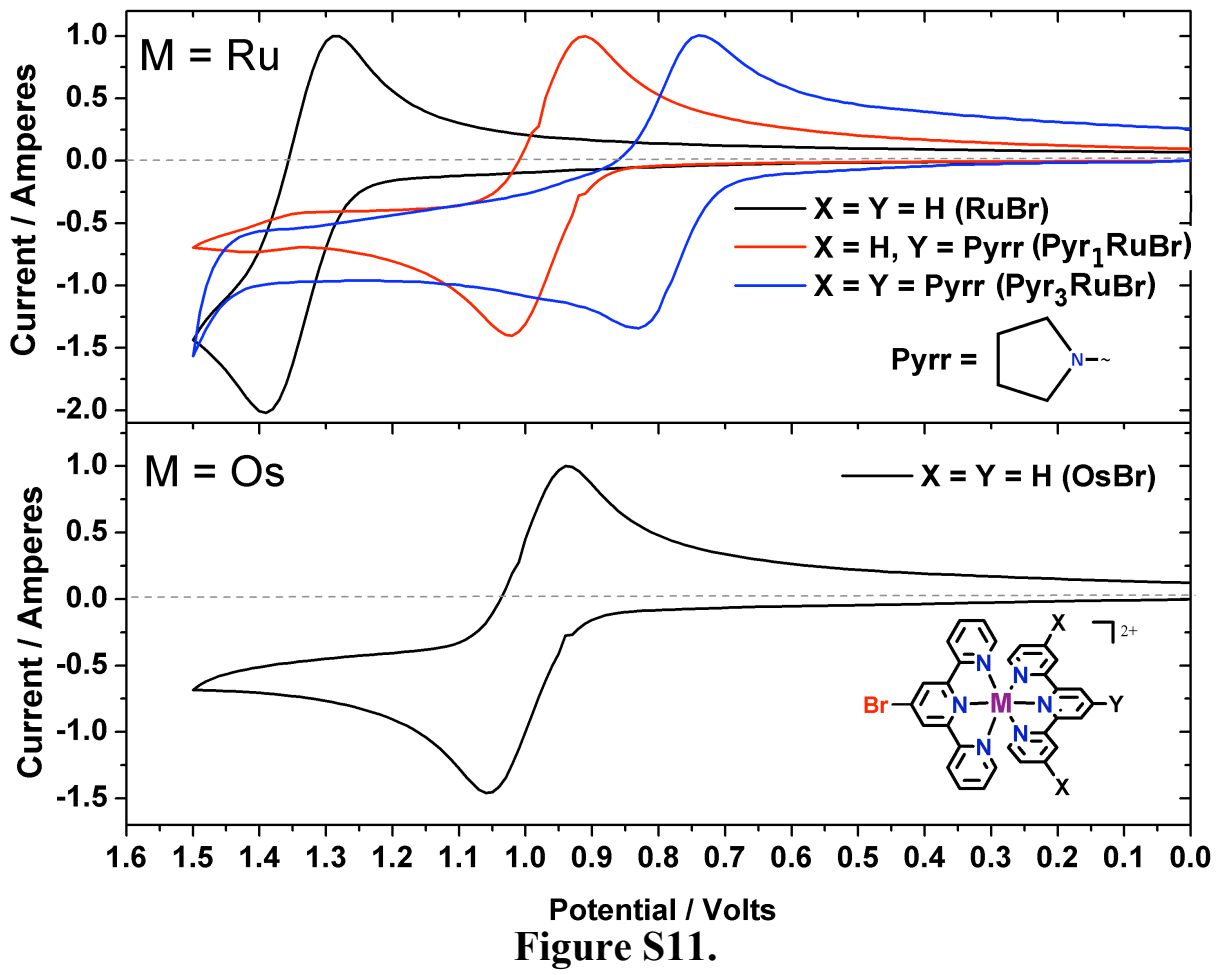




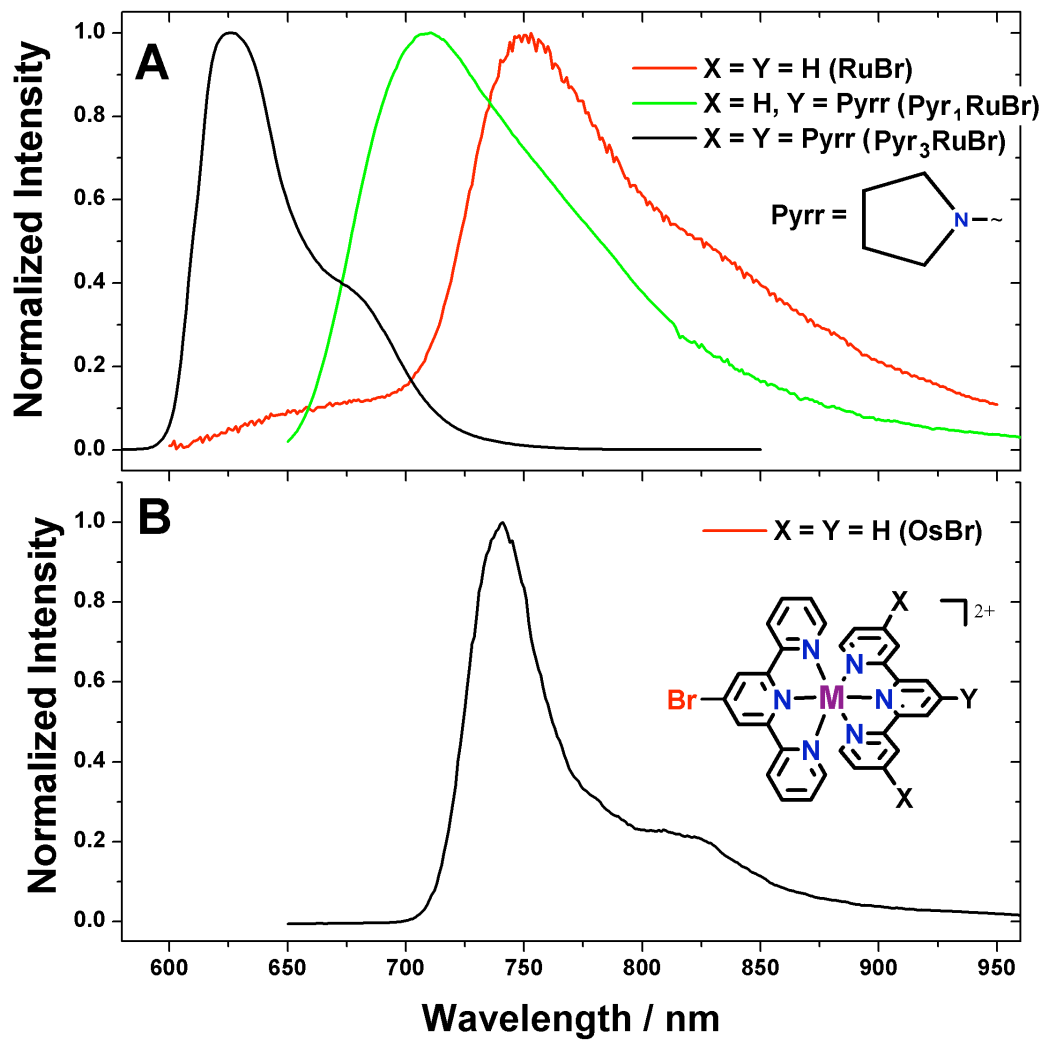

Figure S12.

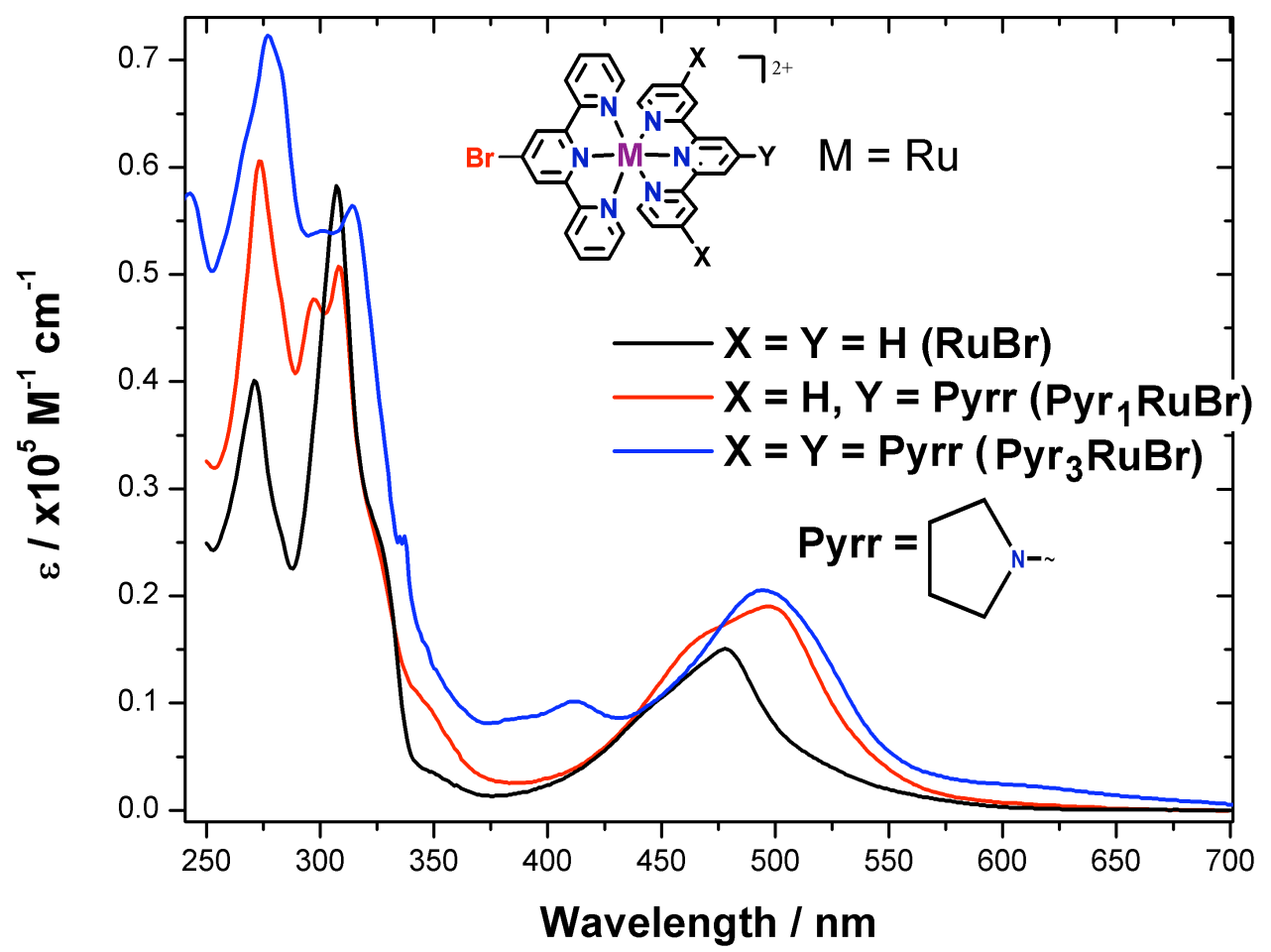

Figure S13. 


\section{References.}

(1) Holbrey, J. D.; Tiddy, G. J. T.; Bruce, D. W. J. Chem. Soc. Dalton 1995, 17691774.

(2) Potts, K. T.; Konwar, D. J. Org. Chem. 1991, 56, 4815-4816.

(3) Uyeda, H. T.; Zhao, Y. X.; Wostyn, K.; Asselberghs, I.; Clays, K.; Persoons, A.; Therien, M. J. J. Am. Chem. Soc. 2002, 124, 13806-13813.

(4) Martineau, D.; Beley, M.; Gros, P. C. J. Org. Chem. 2006, 71, 566-571.

(5) Ishii, T.; Fujioka, S.; Sekiguchi, Y.; Kotsuki, H. J. Am. Chem. Soc. 2004, 126, 9558-9559.

(6) Gros, P.; Fort, Y. Eur. J. Org. Chem. 2002, 3375-3383.

(7) Stille, J. K. Angew. Chem. Int. Ed. 1986, 25, 508-523.

(8) Wieprecht, T.; Schlingloff, G.; Xia, J.; Heinz, U.; Schneider, A.; Dubs, M.-J.; Bachmann, F.; Hazenkamp, M.; Dannache, J. In PCT Int. Appl. WO2004/039933 A1, 2004.

(9) Constable, E. C.; Ward, M. D. J. Chem. Soc. Dalton 1990, 1405-1409.

(10) Jameson, D. L.; Guise, L. E. Tetrahedron Lett. 1991, 32, 1999-2002.

(11) Case, F. H. J. Org. Chem. 1962, 27, 640-\&.

(12) Constable, E. C. New J. Chem. 1992, 16, 855.

(13) Jones, W. E.; Smith, R. A.; Abramo, M. T.; Williams, M. D.; Vanhouten, J. Inorg. Chem. 1989, 28, 2281-2285.

(14) Sauvage, J. P.; Collin, J. P.; Chambron, J. C.; Guillerez, S.; Coudret, C.; Balzani, V.; Barigelletti, F.; Decola, L.; Flamigni, L. Chem. Rev. 1994, 94, 993-1019.

(15) Hung, C. Y.; Wang, T. L.; Jang, Y. C.; Kim, W. Y.; Schmehl, R. H.; Thummel, R. P. Inorg. Chem. 1996, 35, 5953-5956.

(16) Maestri, M.; Armaroli, N.; Balzani, V.; Constable, E. C.; Thompson, A. M. W. C. Inorg. Chem. 1995, 34, 2759-2767.

(17) McCusker, J. K. Acc. Chem. Res. 2003, 36, 876-887.

(18) Balzani, V.; Juris, A.; Venturi, M.; Campagna, S.; Serroni, S. Chem. Rev. 1996, 96, 759-833.

(19) Juris, A.; Balzani, V.; Barigelletti, F.; Campagna, S.; Belser, P.; von Zelewsky, A. Coord. Chem. Rev. 1988, 84, 85-277. 